How Children Talk About Events: Implications for Eliciting and Analyzing Eyewitness Reports

\author{
Sonja P. Brubacher \\ David La Rooy \\ Royal Holloway University of London \\ Jason J. Dickinson \\ Montclair State University \\ Debra Ann Poole \\ Central Michigan University \\ Author Note
}

Carole Peterson

Griffith University Memorial University of Newfoundland

Sonja P. Brubacher, Centre for Investigative Interviewing, Griffith Criminology Institute, Griffith University; Carole Peterson, Department of Psychology, Memorial University of Newfoundland; David La Rooy, School of Law, Royal Holloway University of London; Jason Dickinson, Department of Psychology, Montclair State University; Debra Ann Poole, Department of Psychology, Central Michigan University.

Transcript examples and data sets for re-analyses were collected for studies supported by National Science Foundation grants SBR-9409231, SES-0718856, SES-0921161, SES-0718889, and SES-0921227, the Australian Research Council Linkage Grant LP120200095, the Natural Sciences and Engineering Research Council grant 513-02 (Canada), and the Social Sciences and Humanities Research Council (Canada). Correspondence concerning this article should be addressed to Sonja Brubacher, Centre for Investigative Interviewing, Griffith Criminology Institute, Mt. Gravatt campus, Griffith University, 176 Messines Ridge Road, Mt. Gravatt QLD 4122, Australia. E-mail: s.brubacher@griffith.edu.au 


\begin{abstract}
Legal and social service professionals often question whether various features of young witnesses' responses during interviews are characteristic of children's event reports or whether these features are concerning findings that reflect degraded memory, outside influence, or other phenomena. To assist helping professionals and researchers who collect data through interviews, we aggregated findings from child eyewitness studies and revisited transcript sets to construct fifteen principles that capture how children talk about events. These principles address children's earliest event narratives, how children report information as interviews unfold and typical features of their narratives, threats to the accuracy of answers, the influence of interviewers' language on children's styles of reporting, how testimonies compare across multiple interviews and multiple witnesses to the same event, and the structure of accurate and inaccurate reports. A summary table highlights the implications of these principles for interviewers and the decision-makers who analyze children's reports.
\end{abstract}

Keywords: children, eyewitness memory, event reports, narrative structure

\title{
Highlights
}

- Transcripts from eyewitness studies provide rich insights into how children talk about events.

- Fifteen principles summarize findings and justify guidelines for eliciting children's reports.

- These principles can help professionals understand confusing and inconsistent reports.

- Memory researchers can advance knowledge by providing typical narratives from each age group. 


\section{How Children Talk About Events: Implications for Eliciting and Analyzing Eyewitness}

\section{Reports}

The development of best-practice standards for conducting forensic interviews of children is the most visible contribution to emerge from research on young witnesses' testimony (Lamb, Brown, Hershkowitz, Orbach, \& Esplin, 2018; La Rooy et al., 2015; Saywitz, Lyon, \& Goodman, 2018). But there is another useful product from this research: Around the world, laboratories house thousands of transcripts which document how children typically talk about events. Behind the scenes, it is the patterns in these transcripts that are valuable to the interviewers and attorneys who contact eyewitness and memory experts with questions. Oftentimes, these questions center on a specific feature of a child's report, and the issue is whether that feature is characteristic of children's event narratives or a concerning finding that reflects degraded memory, outside influence, or some other phenomenon. Understanding how children talk about events in their lives is especially relevant for forensic cases but has numerous applications, from advising mandated reporters to helping developmental researchers elicit children's experiences.

For this paper, we reviewed published findings and revisited transcript sets to construct fifteen principles that capture how children talk about events. Four considerations guided our selection of principles and the representative studies that illustrate those principles. First, we focused on children who actually experienced the events they were asked to describe, although in some studies they were also exposed to misinformation before interviews and/or questions about fictitious happenings. Next, we constrained our review to cognitive influences on children's reports rather than social influences, such as expectations of consequences and caregiver supportiveness, which limited our discussion to topics affecting children's ability to describe an 
event (rather than willingness to share their experiences). Third, each principle had to address an issue or misunderstanding that frequently arises among adults who are unfamiliar with children's event reports. For example, we have had discussions with professionals who thought there was no point in interviewing a 2-year-old, assumed that minor errors in children's event descriptions called into question the reliability of allegations, and concluded that conflicting answers to differently-phrased questions indexed lack of memory for an event. In each of these cases, the professionals inappropriately discounted children's ability to provide meaningful testimony. We have also experienced the opposite problem, when decision-makers facing implausible, incoherent, and contradictory testimonies failed to realize that such reports are atypical of children's descriptions of experienced events. Although our principles cannot, disembodied from the overall context of cases, determine how evidence should be interpreted, we hope they will help professionals focus on the most significant features of children's testimony.

Finally, we wanted this set of principles to be nontechnical in the sense that no special knowledge of linguistics, memory, or other specialty fields was required to spot the principles at work in interviews. This goal necessarily eliminated information that could be critical in some cases, including discussions of how individual differences in temperament, culture, and the presence of medical or cognitive conditions can impact the structure and content of event reports. We felt comfortable setting aside these topics, however, because there is wide variability in children's behavior even within a given demographic group. As a result, discussions of average differences across groups of children could encourage adults to question any behavior that deviates from a general description. In practice, professionals working with an unfamiliar demographic, or rendering decisions that hinge on a developmental detail, will need to contact relevant experts for guidance. 
The fifteen principles represent findings from varied methodologies, including analog paradigms with staged events, studies of memory for naturally-occurring events (e.g., traumatic injuries), and analyses of witness interviews from real-world investigations. Unlike discussions of the linguistic devices that emerge in narratives as children mature (Feltis, Powell, \& Roberts, 2011; Hudson \& Shapiro, 1991), our paper addresses issues practitioners notice when they review interviews. The principles we summarize dispel some misunderstandings about children's event reports, justify widely-held recommendations for eliciting their testimonies, and provide the foundational knowledge professionals need to make sense of narratives that are sometimes confusing and inconsistent.

We begin by discussing children's earliest event narratives and the way they report information as interviews unfold. We describe some typical features of their narratives, threats to the accuracy of their answers, the influence of interviewers' language on their styles of reporting, and how testimonies compare across multiple interviews and across multiple witnesses to the same event. Our final principle addresses the structure of accurate and inaccurate reports. We end the discussion of each principle by highlighting some implications for interviewers and the myriad decision-makers who analyze children's reports. (See Table 1 for a summary of principles and implications).

\section{Children Describe Past Events From the Time They Can Talk}

Children begin verbally encoding and talking about events in their lives somewhere around their second birthday, and they remember some of these events for many years. One way to study the fate of these early memories is to ask children to think of their earliest recollections and to share as much as possible about the events. Compared to studies that asked adults about their earliest memories, this approach has several advantages: Parents can confirm the accuracy 
of children's reports and independently date them, the events occurred recently from the parents' perspective (which should improve the accuracy of their recollections), and the children can be followed longitudinally to understand what happened to these memories over time. In several studies that collected children's earliest recollections, the majority or a sizeable minority of North American Caucasian children of preschool and elementary school ages described earliest memories from when they were 2 years old, and some memories were even earlier (Peterson, Grant, \& Boland, 2005; Peterson, Wang, \& Hou, 2009; Peterson, Warren, \& Short, 2011). These memories captured a wide array of content, including stressful injuries, exciting trip adventures, and events that seemed mundane to parents who were surprised their children remembered these things at all (e.g., once climbing out of a crib, a sibling putting his diaper on backwards).

The early emergence of autobiographical recall in studies of children's memories seems to conflict with discussions of childhood amnesia (also called infantile amnesia), which is the inability later in life to recall events from very early life. (For reviews, see Bauer, 2015, and Madsen \& Kim, 2016.) Typically, adults date their earliest memory from when they were between 3 and 4 years of age (although a sizeable minority of adults recall a few details of events that occurred when they were age 2 or, sometimes, even younger; Rubin, 2000). If many children remember some events that occurred when they were 2 years old, then why do adults usually date their first memory about age 3 or 4 years? Studies have found two reasons: (1) some memories are forgotten, and (2) people make systematic errors when dating their memories, such that events often occurred at an earlier age than what people recall.

The eventual loss of most early-life memories has been documented by longitudinal research that measured the fate of 4- to 9-year-olds' three earliest memories across 2-year (Peterson et al., 2011) and 8-year delays (Peterson, Hallett, \& Compton-Gillingham, 2017). In 
follow-up interviews, children who had been 4 or 5 years old at the time of initial interviews infrequently identified as earliest the same memory they had recalled in their first interview, although some of the older children did. When interviewers provided cues about memories that were not spontaneously recalled, however, these memories were often still intact. But former 4to 5 -year-olds simply could not remember about $39 \%$ of their previously identified earliest memories 2 years later, even after cueing, and $46 \%$ were lost after 8 years. Furthermore, 8 years after their initial interview, a fifth of the content former 4- to 5-year-olds recalled contradicted what they had said originally. By contrast, older children seldom provided contradictory information. Together with evidence from other memory paradigms, these results show that children's earliest memories are vulnerable to forgetting but that memories retained until at least age 6 or 7 years are more likely to survive (Newcombe, Lloyd, \& Balcomb, 2012; Newcombe, Lloyd, \& Ratcliff, 2007). Other studies have found that the memories most likely to disappear are those that are devoid of emotion and not narratively coherent (i.e., lacking elaborative information about who, where, and what; Peterson, Morris, Baker-Ward, \& Flynn, 2014; Peterson et al., 2017).

Wang and Peterson $(2014,2016)$ clearly documented the finding that people gradually move up the date they report for specific, early memories (see also Reese \& Robertson, 2019). In these studies, children described their three earliest memories and the reports were dated not only by the children but also by their parents. When children who were initially between 4 and 9 years of age were re-interviewed after 2 and then 8 years (Wang \& Peterson, 2016), specific early memories were dated 4 months later after 2 years and 17 months later after 8 years. This phenomenon (that each redating advanced the age associated with remembered events) was particularly evident for memories parents identified as occurring prior to children's $4^{\text {th }}$ birthday 
and memories from the youngest children (cf. Reese \& Robertson, 2019). Extrapolating, it is likely that many memories reported by adults are also misdated, and events that cannot be externally dated (for example, by sibling births or house moves) may have occurred considerably earlier than the ages adults reported. Indeed, Wang et al. (2017) found just this: When college students recalled and dated their earliest memories, independent dating by their parents showed that for memories prior to children's $4^{\text {th }}$ birthday (according to parental dating), college students misdated their memories to many months later. Thus although textbooks state that the average age of people's first memories is around 31/2 years, this body of research suggests that it is actually more likely to be $2 \frac{1}{2}$ years.

There is an important caveat for professionals who apply these findings to forensic cases: The studies described here asked children to nominate which events they remembered, and memory performance would likely be less impressive for some events selected by adults. Nonetheless, these findings counter the assumption that children who are only 2 or 3 years old cannot provide valuable information. (For a case example, see Goodman, Ogle, McWilliams, Narr, \& Paz-Alonso, 2014.) Still, very young children are challenging witnesses who often have little to say and do not stay on topic. Interviewers can support this age group by scheduling interviews for times when children are usually alert and giving them adequate time to think and respond (Poole, 2016). Professionals who analyze the resulting reports should never dismiss a claim based solely on a child's age, but they need to consider the information discussed next: How age at the time of the event and the amount of time that has elapsed impact the accuracy of children's reports.

\section{The Delayed Reports of Children Who Were Preverbal During the Event Are Sparse and/or Riddled With Errors}


Children typically cannot linguistically access memories of experiences that occurred before their language skills were sufficiently developed to enable them to talk about events from the past (around their $2^{\text {nd }}$ birthday; but see Bauer, Kroupina, Schwade, Dropik, \& Wewerka, 1998). In fact, most children cannot verbally recall any events from infancy or toddlerhood. To study children's ability to describe highly salient events, one research team recruited children taken to a hospital emergency room due to trauma injuries, such as bone fractures, gashes requiring suturing, and burns, and then visited them in their homes within a few days of their treatment (Peterson \& Bell, 1996). Assistants obtained a record of what had occurred by talking with parents and other adults who had witnessed each child's injury and hospital treatment, and they interviewed all children who possessed the language skills to respond. These interviews probed for a wide range of information about who, what, where, and when; sequences of actions; and so forth. The adult witnesses provided the "gold standard" for scoring children's accounts.

Children who were between 3 and 13 years of age at the time of injury provided information that was mostly accurate - not only during an interview within days of the injury but also in subsequent interviews that occurred for some children at delays of 2,5 , or 10 years (Peterson, 1999, 2015; Peterson \& Whalen, 2001). However, a considerable transition occurred among children injured between 1 and 2 years of age (Peterson \& Parsons, 2005; Peterson \& Rideout, 1998). Those just over 2 years but less than 3 (26 to 34 months old at the time of injury) were able to verbally describe their injuries in the initial interview and continued to recall a considerable amount of information over subsequent years. Moreover, about $75 \%$ of their recalled information was accurate in their initial interview and also 1, 2, and 5 years later. The situation was quite different for children who were just a few months younger, however. The youngest children, who were 13 to 18 months of age at the time of the injury, lacked the verbal 
skills to be interviewed initially, and most recalled nothing in subsequent interviews several months or years later. The majority of older toddlers (those 20 to 25 months at the time of the injury who could not participate verbally in an initial interview) recalled nothing as well. However, some did provide information in later extensive interviews, although this information was problematic in two ways. A year or 18 months later, among children who could recall anything at all, only about $63 \%$ of the information they provided was accurate (Peterson \& Rideout, 1998). Five years later, in a study that combined older and younger toddlers, those former 13 to 23 month olds who could recall anything about their injury had an accuracy rate of only $41 \%$ (Peterson \& Parsons, 2005). Thus the accuracy of information provided during extensive interviews was not very high and deteriorated over time. Furthermore, of those former toddlers who recalled anything at all, 5 years after injury $70 \%$ provided a report that amalgamated pieces of the target event with pieces of other events. These children knit disparate parts of different events together to create a coherent report, although they did not recognize that they had created such a mixture.

In sum, having the linguistic ability to talk about the past, at the time of an event, predicts whether the event is later recalled at all as well as the accuracy of account details: Delayed reports from children who were preverbal at the time of the event are typically minimal and riddled with errors. These findings explain why interviewers compromise eyewitness accuracy when they probe for specific information about events that occurred when children were preverbal. When such probing has occurred, or when children's reports are more elaborate than would be expected from the circumstances, professionals who analyze reports should consider the roles that significant adults and prior interviews might have played in developing children's event narratives. 


\section{Children Report in Piecemeal Fashion Across Open-Ended Prompts}

Forensic interviewers are trained to elicit event narratives by delivering a series of openended prompts, such as "What happened?" and "Then what happened?" There is no clear definition of what qualifies as an open-ended prompt, but a guiding rule is that these are prompts designed to elicit responses longer than just a word or two (La Rooy et al., 2015).

Although privileging open-ended prompts is the guiding maxim of investigative interviewing, interviewers typically fall short of this recommendation (Benson \& Powell, 2015; Cederborg \& Lamb, 2008). In a set of transcripts from New Zealand, for example, interview specialists delivered far more direct (wh-) and option-posing questions during substantive (case issues) interview phases ( $57 \%$ and $20 \%$ of all prompts, respectively), and the percentage of openended prompts was no higher in the first than the second half of the conversations (Wolfman, Brown, \& Jose, 2016). On average, these social workers and police officers delivered about four open-ended prompts before resorting to a direct question, indicating that many interviewers narrowed the focus of questioning even sooner. As the study authors explained, "Interviewers were not working to elicit children's narratives with minimal input by relying on very openended prompts" (p. 591).

It is possible that interviewers shift prematurely to focused questions when they believe that children have exhausted the ability to retrieve information via free recall. An interesting characteristic of event reports would encourage this behavior: Children typically report in piecemeal fashion, mentioning one or two themes in response to a prompt and then gradually adding information, in small packages, as conversation continues. Because children tend to describe only a little about something and then stop, adults might assume they have finished talking when, in fact, the children have much more to say. The following responses to open- 
ended prompts, from a 7-year-old, illustrate this pattern of repeatedly saying a little and then waiting for another prompt (transcript for Poole \& Dickinson, 2011):

(Prompt to tell about a science event.)

Child: Well, we have these little pulleys and a weight, and we lifted that up and see what was heavier.

(Prompt to tell more.)

Child: Well, next I think we got, like, a little container. The lid was on the bottom. There was little paperclips with string attached. And then, and there was a little magnet, and we turned the magnet and see which one went farther. And I think the black string went farther.

(Prompt to tell something else.)

Child: Well, then we made paper airplanes and saw which one went farther. And mine went the farthest. Mine would have, like, flewn (sic) right out the door!

As Figure 1 (panel a) reports, many children in the study that generated this example reported additional mini-events as interviewers continued to deliver open-ended prompts, and this was true even among the youngest witnesses (4 and 5 years). Other analyses have also found that although young children report less information than older children, their pattern of reporting is similar. For example, Lamb and colleagues found that almost half the information children provided during NICHD interviews appeared in responses to open-ended prompts regardless of age (Lamb, Sternberg, Orbach, Esplin, Stewart, \& Mitchell, 2003). As they summarized, even 4-year-olds can "provide substantial amounts of forensically important information" in response to open-ended prompts (Lamb, Orbach, Hershkowitz, Esplin, \& 
Horowitz, 2007, p. 1208).

It is challenging to know when children have exhausted their ability to freely recall new information because they periodically fail to retrieve new details even though they are capable of doing so. To illustrate this stop and go process, Figure 1 (panel b) shows the percentage of children in Poole and Dickinson's (2011) study who reported an additional mini-event after a previous prompt failed to elicit one. It is interesting that even the youngest children sometimes recalled event components interviewers would have missed had they abandoned open-ended exploration whenever a prompt failed to produce a new event component. Consider this example from a 6-year-old:

Interviewer: I want to know what happened that day in the science room. Start with the first thing that happened and tell me everything you can, even things you don't think are very important.

Child: $\quad$ Mmm, I don't really...know. Cause it's been a while since.

Interviewer: Tell me more about what happened in the science room.

Child: $\quad$ Um, we made paper airplanes.

Also confusing is the fact that children, including the following 10-year-old, sometimes use "I can't remember" and related phrases to end a talking term (rather than to accurately convey the state of their knowledge):

Interviewer: I want to know what happened that day in the science room. Start with the first thing that happened and tell me everything you can, even things you don't think are very important.

Child: Umm. Well. We did science experiments like having a hose and putting two different kinds of, um, attachments on the end and seeing how different 
they sound. We also, um, filled balloons with something . . and Mr.

Science tried to put a sticker on my shoulder, and it wouldn't stay on.

That's pretty much it. Oh. Then I got money. That was pretty much it.

Interviewer: Tell me more about what happened in the science room.

Child: $\quad$ I can't remember any more.

Interviewer: Sometimes we remember a lot about how things looked. Tell me how everything looked in the science room.

Child: It was a really bright room. It was . . well the walls were really bright. Um. There was either an apple or a tomato timer. It was really funny lookin'. And I think that I was sitting um by either a table or a desk that was really, really white. And there was a big filing cabinet. And there was stickers in it. That's all I can remember.

Because children report in piecemeal fashion across open-ended prompts, often report novel information after failing to provide anything substantially new in response to an earlier prompt, and frequently say they have no more to say, experts advise interviewers to (a) prolong open-ended prompting by delivering a series of differently-worded prompts, (b) use facilitators (also called minimal encouragers or still-your-turn feedback; e.g., "Uh huh") to turn conversation back to the child, and (c) combine invitations ("Tell me what happened") with cued-invitations that ask children to expand on something they already mentioned ("Tell me about the time he took pictures") (Lyon, 2017). Professionals who analyze interviews should realize that children may not be knowledgeable about the type and depth of information required in an investigation. After a child has said, "That's all," interviewers may consider moving to a different portion of the narrative or using a different open-ended prompt to elicit further recall. Interviewers who 
need to defend why they continued to deliver open-ended prompts to a reticent child can cite the principle we describe next.

\section{Children Maintain Accuracy Across a Series of Differently-Worded Open-Ended \\ Prompts}

In many eyewitness studies, interviewers delivered a fixed set of open-ended prompts regardless of whether children responded to individual prompts or not, which makes it possible to determine whether the accuracy of responses maintained or declined as questioning continued. One study (Poole \& Lindsay, 2001, supplementary report) generated fine-grain data about the accuracy of responses to five open-ended prompts among children who were interviewed three times: immediately after the target event and then about three and four months later, with the delayed interviews occurring after exposure to false information about the event.

Two findings stood out. First, the information children reported in response to openended prompts was not always accurate; instead, they sometimes inserted detail errors (e.g., reversing the order of events), suggested information, and intrusions (e.g., events encountered in school) into narratives. Collapsing over these types of errors, about $16 \%$ of the information that 3- and 4-year-olds reported in response to the first open-ended prompt was inaccurate in the second interview, compared to a $10 \%$ inaccuracy rate from the 7 - and 8 -year-olds. These are average values, however: Some children reported no or little inaccurate information, whereas others reported more. Inaccuracy rates vary across studies with different events and interview delays, but eyewitness studies typically find some errors even during the free-recall phase of interviews (e.g., 11\% of meaningful information units from 5- and 6-year-olds olds who experienced a medical procedure one time; Goodman, Quas, Batterman-Faunce, Riddlesberger, \& Kuhn, 1994). 
The surprising finding from Poole and Lindsay (2001) was that error rates were similar across the five prompts - even though interviewers continued prompting children who said they had nothing more to say. For example, the 3- and 4-year-olds had nearly the same inaccuracy rate for newly added information in response to the first and last open-ended prompt, and so did the 7- to 8-year-olds. This pattern of similar error rates for information added early and late in a short series of differently-worded open-ended prompts was also true for an interview conducted about a month later. For example, at that time $2 \%$ of the information that 7 - and 8 -year-olds reported in response to the first open-ended prompt reflected false suggestions, but this age group added no new suggested information in response to a fifth open-ended prompt.

These findings should reassure interviewers that children do not necessarily interpret continued open-ended prompting as an invitation to speculate. The consistent accuracy rate across a short series of open-ended prompts also tells professionals who analyze testimonies not to place more weight on early interview responses. There is a caveat we mention next, however: Children who become bored with conversation sometimes lose track of the topic.

\section{All Age Groups Sometimes Drift Off Topic During Conversation}

As adults, we trust that our conversational partners will keep the topic of conversation in mind, and we are annoyed when other people steer discussions in new but unwanted directions. Young children, however, do not feel similarly constrained by an overarching topic. In daily conversation, a typical 3 1/2-year-old can stay on topic for more than two conversational turns, but as many as $25 \%$ of their remarks will be off topic, and even 5 -year-olds tend to maintain topics for only five turns (Gotzke \& Gosse, 2009).

During interviews, children's narratives sometimes drift off topic due to mere lapses of attention, but other times they start talking about something new because they interpret a 
question differently than an adult would. Because researchers who analyze children's descriptions of staged events know what the target events were, they also know that sudden mention of a father taking pictures of a child, or the death of a treasured pet, was nothing more than a wandering mind. In forensic cases, however, such meanderings are confusing. When this occurs, follow-up questions about happenings that were unrelated to the matters under investigation can trigger the development of fictitious, and sometimes bizarre, stories.

Interviewers have three antidotes for topic drift: topic shifters (short phrases that warn children when interviewers are changing the topic of questioning), topic markers (words in interview prompts that repeat names of the people and actions of interest), and topic drift checks (questions that clarify whether a child is still talking about the matter under investigation) (Poole, 2016). Professionals who analyze children's testimony cannot control how interviews unfolded, but they can be skeptical of unexpected detours, and they can ask adults in a child's life whether an unexpected narrative matches other caregiving locations or innocuous events the child might have remembered. It is also important not to discredit a generally coherent account of an event simply because a fatigued child began answering questions by parroting pages from a beloved book or a favorite cartoon show.

\section{Young Children Use Words That Come to Mind and Ones They Can Easily Pronounce}

Many language phenomena make it challenging to understand children's event reports. Consider the following comments from three children in one analog study (transcripts for Poole \& Lindsay, 2001):

And there was a big potato, and I can play in 15 minutes.

There was a potato kind of clock, and Mr. Science put it for 6 minutes to be with him. First he got out this potato thing, and then he set it at five o'clock. 
Potatoes populated the memory reports in this study, despite the fact that there had been no potatoes - or clocks - in sight. The following two children were a little more helpful:

There were a timer, like, looked like a potato, potato.

I saw a table, and I saw this little red potato it was, it looked like a red potato but it wasn't, and it was a timer.

The object that numerous children described as a potato was a red kitchen timer, shaped like a tomato, that research assistants set to 15 minutes at the start of each child's session. In addition to humorous substitutions like this one, some children make errors that would be more serious in an investigation, such as when one child repeatedly referred to hand sanitizer ("soap") as "dope" (Poole, Dickinson, \& Brubacher, 2014).

It is not uncommon for young children to reverse the order of consonants in a word, delete a consonant, or replace a sound with one that is easier to say. In addition to pronunciation errors, they sometimes use words they are familiar with as stand-ins for words they do not know, and their first understanding of a word may not map onto the adult meaning for that word. A ubiquitous example in case materials involves "yesterday," which young children first use to mean "sometime in the past" (Grant \& Suddendorf, 2011).

Interviewers can avoid confusion by not guessing what children said and by delivering clarifying prompts for key event features (e.g., "You said he set something. What did that thing look like?"). Due to the technical nature of language issues, professionals who regularly evaluate children's testimonies should refer to a primer on the topic, such as Walker's (2013) book, and consult with developmental psychologists or speech pathologists when they need help understanding the significance of a critical event detail. Sometimes, the best explanation for a child's comment will not become clear until the entire context of the case is considered along 
with patterns of answers throughout the interview.

\section{Event Narratives Often Contain Nonfluencies and Expressions of Uncertainty}

Children and adults alike produce a variety of nonfluencies when they describe eventsincluding false starts (phrases that stop abruptly), repetitions, fillers ("Well"), and correctionswhich linguists call mazes, as in this example (transcript for Poole \& Lindsay, 2001):

First, I forgot what the first thing was. The first, we made a telephone and, and, and we made a, we did, we made something, you put baking soda and pop into a balloon and it blows up. And then we made, and we did, but I can't, I only can remember three things. And we, we, we had a red egg it looked like a egg and it had something in there, you could put, sit, you could put on the paper and words came on there that's what. That's all I can remember of Mr. Science now. Now what else do you want to talk about? Mazes appear in narratives throughout development, with some types occurring more often as children mature and more frequently monitor what they are saying. The density and type of nonfluencies depends on many factors, however. As a general rule, children show more nonfluencies when they are constructing narratives (rather than participating in casual chit-chat), communicating about abstract concepts, and formulating stories for the first time, and children with language or learning difficulties produce more nonfluencies than their typically developing peers (Fiestas, Bedore, Peña, \& Nagy, 2005). It is also common for children to indicate uncertainty by inserting phrases like "I think" into narratives. These qualifiers tend to drop out of responses when interviewers repeat questions within a single interview, but frequency increases in interviews conducted a long time after events, when memories have faded (Poole \& White, 1993).

Because nonfluencies and expressions of uncertainty are normal characteristics of event 
narratives, interviewers should not assume that these features imply weak memories (which could lead them to terminate conversations prematurely). Similarly, professionals who analyze transcripts should not claim that a normal density of these features is evidence of impoverished memory, nor should they assume that the lack of these features, especially among children who have told their stories several times, is evidence of a fabricated or coached story.

\section{Children's Narratives Contain Detail Errors, and Young Children Have Weaker Filters for Some Types of Errors}

A number of mechanisms insert description errors into largely accurate reports. Some errors are pure fabrications that appear when children try to flesh out sketchy memories. Other times, these errors reflect general representations children have about how things usually look or happen. For example, one research participant described a drop ceiling that did not exist in the laboratory room, perhaps because he retrieved a general representation of ceilings he had seen in other nonresidential buildings (transcript for Poole \& Lindsay, 2001).

One explanation for erroneous but event-consistent intrusions is provided by Fuzzy-trace theory (Reyna \& Brainerd, 2011). Fuzzy-trace is a dual process theory wherein two separate types of memory traces are encoded and stored following an experience: verbatim traces representing surface features of events and their contexts, and gist traces representing patterns, themes, and meanings. When people flesh out reports with information that is false but consistent with the meaning of an event, they are relying on gist rather than verbatim traces. Earlier we mentioned how children who were very young at the time of an event often amalgamate multiple authentic memories, but even older children and adults produce these memory conjunction errors when deficient inhibitory mechanisms fail to filter event-irrelevant thoughts that are activated during memory retrieval (Devitt, Monk-Fromont, Schacter, \& Addis, 
2016; Nahum, Bouzerda-Wahlen, Guggisberg, Ptak, \& Schnider, 2012).

Memory conjunction errors are a type of source confusion in which people report information from an event other than the one being discussed. When describing a trip to the zoo, for example, one 4-year-old research participant mentioned patting the bunnies. His mother later explained that the only animals they saw at the zoo were wild, but he had touched rabbits at the pet store the week before. Such errors occur when children fail to monitor the contextual (verbatim) details that specify the origin (source) of specific memories.

According to the source-monitoring framework (Johnson, Hashtroudi, \& Lindsay, 1993), people identify the source of information retrieved from memory through heuristic or systematic judgment processes. Heuristic judgments rely on quick rules-of-thumb and may occur without conscious awareness. For example, you might swiftly identify the source of sad news when you mentally replay the voice that delivered it. Systematic judgments involve decision-making. For example, you might decide that you last ate rhubarb pie at a neighbor's pool party, rather than a different social event, because you recall the muggy day and the pie's soggy crust. The ability to make source decisions develops with age (see Foley, 2014, for a review). Compared to older children, young children are less likely to bind related details together in memory (Lee, Wendelken, Bunge, \& Ghetti, 2016; Lloyd, Doydum, \& Newcombe, 2009), tend to forget more contextual information (Scarf, Gross, Columbo, \& Hayne, 2013), are poorer at reasoning about the sources of their memories, and have weaker filters for gating out source-irrelevant details (Foley, 2014). Source errors are especially prevalent while children are rapidly acquiring general information about the world, possibly because memory for content, rather than the myriad details that specify source, is most important for building concepts (Foley, 2014; Sommerville \& Hammond, 2007). 
Children frequently make source errors when they recall specific episodes of multiple similar events (Brubacher, Powell, \& Roberts, 2014). Indeed, in analog studies nearly all errors about repeated events are "internal" intrusions in which children report experienced details but confuse the occurrence (source). A sample of 455 children collapsed across several studies illustrates this principle (Brubacher, Earhart, Roberts, \& Powell, 2018; Brubacher, Glisic, Roberts, \& Powell, 2011a; Brubacher, Roberts, \& Powell, 2011b; Brubacher, Roberts, \& Powell, 2012; with 51 children from unpublished data). Among a group of 4- to 8-year-olds who participated in four events that included some varying details from one occurrence to the next, the mean number of fabricated details (not from the event set) during free recall was just 0.55 (range $=0.00$ to 8.00 ). As in a single-event study that counted spontaneous detail errors in free recall (Poole \& Lindsay, 2001), there was no relationship between age in months and the number of these errors. But unlike the low rate of fabrications, these children often confused details from different occurrences of the repeated event (saying, for example, that the dog story read on the second day was heard on the first). With increasing age, children were less likely to attribute variable details to the wrong event occurrence, which is expected given the typical developmental improvements on source-monitoring tasks. (See Figure 2 for error rates as a function of age.) Internal intrusions also dominated among children who answered whquestions about a particular event occurrence (e.g., "What toys did you count, the first day?"), and the frequency of both internal and external intrusions in responses to wh-questions declined with age (see Figure 2).

What do these data tell us about how children report events? Although responses to openended and directive questions included intrusions, the majority were source errors rather than fabrications. In other words, children with repeated experiences are more likely to confuse 
details across occurrences than to report things that never happened. Studies involving multiple interviews add a related finding: Children who experienced multiple events are less consistent across interviews than those who experienced a single event, but only when internal intrusions are coded as inconsistencies (Price, Connolly, \& Gordon, 2016).

In sum, studies that coded detail errors support the recommendation to rely heavily on open-ended prompts because these prompts often elicit low rates of fabrication errors. Findings from these studies also warn us not to discredit the gist of a narrative simply because minor details are inconsistent with physical evidence or a child's past testimony — and this is especially important when the child is young or has experienced multiple similar events. However, the fact that children sometimes confuse details from related events should not provide fodder for decision-makers to say that anything a child reports must have happened at some time or place. This is because failures to inhibit irrelevant information and to monitor the source of information can lead to the more substantial errors we describe next.

\section{Focused Questions Often Yield Less Accurate Responses Than Open-Ended Prompts}

Best-practice guidelines advise interviewers to rely heavily on prompts that encourage witnesses to provide elaborative responses without constraining the content of their answers (Lyon, 2017). Open-ended prompts, which allow children to follow their own trains of thought, typically elicit longer narratives that contain more accurate information than the information returned by more focused questions, such as wh- ("When did she hit you?"), multiple-choice (“Did mommy or daddy give you that bruise?"), and yes-no questions (“Did mommy hit you with a belt?") (Hutcheson, Baxter, Telfer, \& Warden, 1995; Peterson \& Biggs, 1997; Peterson, Dowden, \& Tobin, 1999). Accuracy differences are not always large, though, and in many studies the majority of the information elicited by both types of prompts is accurate (e.g., 
Alexander et al., 2002; Goodman \& Reed, 1986). Nevertheless, there is good reason to be more confident in the information children report when there is no reason to suspect exposure to misleading information and reports were spontaneous (rather than elicited with questions that asked about specific details; Poole, Brubacher, \& Dickinson, 2015).

Many interviewing guidelines were designed either to minimize the need for focused questions (by preparing children for open questions via a practice narrative phase) or to increase children's accuracy in the face of such questions (by delivering conversational expectations during a ground rules phase). But these methods do not eliminate the fact that children sometimes answer focused questions by guessing or retrieving general knowledge that did not originate from the event under discussion. The result of these problems can be answers that contradict previous testimony from the same child, other witnesses' testimony, or physical evidence.

Interviewers can minimize issues stemming from unexpected answers to focused questions by not asking for unnecessary details and by following focused questions with more open-ended prompts (when possible). Professionals who evaluate children's testimonies should take several factors into account before deciding that a poor answer reflects lack of memory, including the child's age, how the question was worded, the length of time since the event, and the level of detail required by the question. These factors can help them decide whether the overall gist of the report is still intact or whether answers to focused questions seriously compromise the coherence of an allegation. This determination should take into account the entire case context, other available evidence, and the issue we discuss next: That focused questions do not always effectively cue memories.

\section{Focused Prompts Do Not Always Effectively Cue Memories}


In forensic transcripts, children sometimes describe a case detail but then deny that information when interviewers raise the issue again by delivering a focused question. These apparent contradictions are also common in laboratory transcripts, even for event components that children remember well. Here a 10-year-old, discussing an event that occurred less than half an hour earlier, spontaneously described how Bonnie showed her an apron but then answered "no" when the interviewer asked, "Did Bonnie show you anything in the room?" (transcript for Poole \& Dickinson, 2014).

Interviewer: We're going to talk about one more thing. Did you see Bonnie in the other room today?

Child: $\quad$ Yes.

Interviewer: Tell me everything that happened while you were with Bonnie, from the time you walked into the room until you came here. Tell me what happened with Bonnie.

Child: $\quad$ She told me her name and what most people call her: the dog lady. And she showed me how she sewed little yarn tails on her do..., on her dog apron. (Next the child provided a detailed description of the event.)

(Four question-answer interchanges)

Interviewer: Did Bonnie show you anything in the room?

Child: Hmm. No. Except the chair. Which really doesn't count.

Despite the fact that the dog apron was highly salient $(82 \%$ of the children described it in response to open-ended prompts), only $34 \%$ of the children in our sample acknowledged the apron event in response to a focused question about showing. This high rate of denials was not due to children thinking they should mention only new information because only $11 \%$ of the 
children who had not mentioned the apron earlier did so in response to the question about showing.

What explains these seemingly inconsistent answers? One problem is that some question wordings suggest restricted meanings that promote "no" responses. For instance, our focused question about "showing" was a poor one because (a) "in the room" implied that the interviewer was interested in objects like tables and chairs, and (b) questions with the word "any" in them (“... do anything else?”, “... say anything?”) often elicit responses of “no” (even from adults; e.g., "Did you have anything for breakfast?" "No...just a bagel.”) (Heritage, Robinson, Elliott, Beckett, \& Wilkes, 2007). It is also the case that some words are vague and, therefore, are less effective memory cues than alternative ways of asking. For example, even adults might disagree about what constitutes "showing" an object to someone, whereas everyone understands what they saw. Therefore, "Tell me what you saw that time with Bonnie" might elicit more information than "What did Bonnie show you?"

Interviewers prevent contradictions when they use broad but concrete questions that ask children to describe what they saw and heard (Poole \& Lindsay, 2001), what people the children already mentioned did, and how they felt about those events (Lyon, Scurich, Choi, Handmaker, \& Blank, 2012). When interviewers need to ask about specific details, it is best to avoid (a) unnecessary words that might restrict children's interpretation of questions and (b) words that children add late to their lexicons. (For example, pajamas and bathing suits might not be "clothes" to a preschooler, so "Was he wearing clothes" could elicit erroneous "no" responses.) When children have contradicted themselves, it is important to ask follow-up questions that might clarify their intent. Finally, professionals who analyze transcripts can strike out contradictions that could have been caused by well-known language or memory phenomena 
before evaluating the content of the remaining information.

\section{Children's Styles of Reporting Are Influenced by Interviewers' Styles of Asking}

As soon as children can share memories from the past, their conversational styles are molded by the conversational styles of their partners (Langley, Coffman, \& Ornstein, 2017). At home, parents with an elaborative style encourage detailed discussions that include talk about the emotional layer of life. Their children, compared to the children of non-elaborative parents, learn to construct more elaborated narratives (Salmon \& Reese, 2016). Early work on ways to encourage detailed responses in interviews led to the inclusion of a practice narrative phase, when interviewers set expectations for the interview by asking open-ended prompts about a neutral event and encouraging children to continue talking (Roberts, Brubacher, Powell, \& Price, 2011; Sternberg et al., 1997).

A fascinating finding is that children tune the specificity of their language to the specificity of interviewers' prompts. When interviewers deliver generic prompts, which ask about what usually happens (e.g., "Tell me what happens when your sister is being mean"), children are more likely to provide generic information than when interviewers prompt episodically (e.g., "Tell me what happened when your sister was mean to you last weekend"; Brubacher, Malloy, Lamb, \& Roberts, 2013; Brubacher, Roberts, \& Powell, 2012; Schneider, Price, Roberts, \& Hedrick, 2011). Children also have a tendency to report generic information when they have strong scripts for the events under discussion (Brubacher, Roberts, \& Powell, 2011; 2012; Hudson, Fivush, \& Kuebli, 1992). The linkage between interviewers' and children's styles is also weaker when interviewers refer to specific instances of abuse using labels that deviate from the way children referred to these instances. For example, Brubacher and colleagues (2013) found that approximately one third of the time, interviewers used a different 
term to refer to an instance (e.g., "the first time") than the one initially provided by the child interviewee (e.g., "the tent"). This behavior was negatively correlated with children's responsiveness in the interview.

Recent research on children's use of event labels has explored how children pick up on interviewers' intentions. For example, one sample of children were asked to describe two out of four similar events: the time they remembered best and another time (Danby, Brubacher, Sharman, Powell, \& Roberts, 2017). The first time children described a specific episode, $60 \%$ required help from the interviewer to identify and label a specific time, but when asked to describe a subsequent episode, only $31 \%$ required additional support. Older children were more likely than younger children to report a specific episode in the first instance, but age differences disappeared for generation of the second label; in other words, amongst children who had learned to nominate a specific episode.

Research on open-ended prompts has revealed other ways in which children are responsive to interviewers' conversational style. Danby, Sharman, Brubacher, Powell, and Roberts (2017) found that breadth prompts (e.g., "What else happened?", which are also called general invitations) encouraged children with repeated experiences of a pleasant, staged event to report more script information (details that were consistent across occurrences) compared to depth prompts (e.g., "Tell me about the part when [disclosed detail]”, which are also called cued invitations). Conversely, children were more likely to provide episode-specific details in response to depth than breadth prompts. These effects occurred despite the fact that interviewers specifically queried children about a particular episode (e.g., "And then what happened, the day you read the police story?"). Although both breadth and depth prompts are needed in interviews, it is likely that narrower depth prompts help focus children's attention on specific occurrences. 
The findings of Danby and colleagues' experimental work reflect results of earlier studies conducted with transcripts of children's interviews about alleged abuse (Feltis, Powell, Snow, \& Hughes-Scholes, 2010; Lamb et al., 2003).

Anecdotally, we have also spotted examples of children learning interviewers' nonverbal behaviors. A particularly salient example involved a 5-year old girl who helped make an instructional film about how to deliver interview ground rules (see Brubacher, Poole, \& Dickinson, 2015, for a review of ground rules research). With an emphatic finger wagging to the tempo of her speech, the student interviewer said, "If I say something and you don't understand, I want you to say, '[interviewer name], I don’t understand."” After the child (eventually) demonstrated proficiency in using this instruction, the interviewer moved on to a rule about correcting the interviewer by saying, "So if I said you had ice cream for breakfast, what would you say?" The girl thought for several seconds, beamed widely, and looked straight into the student's face. To the tempo of her emphatic finger wagging, she replied, “[Interviewer], I don't understand." She was right: She indeed had not understood the goal of the task, but nevertheless had adopted the interviewer's nonverbal behavior.

Research on linkages between styles of asking and answering yield important take-home messages for interviewers and decision-makers. While avoiding unnecessary gestures (Broaders \& Goldin-Meadow, 2010), interviewers can begin by following children's lead, prompting generically when children disclose generically (e.g., Child: "Uncle Jim does mean things." Interviewer: "Tell me all about the mean things Uncle Jim does.") and episodically when children disclose episodically (e.g., Child: "Uncle Jim hit me.” Interviewer: "Tell me everything that happened when Uncle Jim hit you."). A series of generic prompts can be followed with prompts about specific episodes (Brubacher et al., 2012; Connolly \& Gordon, 2014). Ideally, 
interviewers will direct children to episodes by listening for episodic details spontaneously dropped into accounts (e.g., "It's usually only the weekends, but one time Uncle Jim picked me up from school.”) (Brubacher et al., 2013). Because transcripts containing little information about specific episodes may lower children's credibility (Weinsheimer, 2016), professionals who analyze testimony should take into account how often and when the matters under investigation allegedly occurred (because specific details for frequent and long-ago events are not well retained — script memories are more likely to dominate), and they should consider whether interviewers adequately probed for specific episodes before concluding that specifics were unexpectedly sparse in a narrative.

\section{Children Recall New Information in Subsequent Interviews}

Due to a memory phenomenon called reminiscence, children and adults who describe an event on multiple occasions often include new information in each successive report (La Rooy, Lamb, \& Pipe, 2009; Poole \& White, 1995). This illustrates one of the ways that memory is dynamic: Depending on the moment of recall, witnesses unpack their memories in different ways. Reminiscence occurs during a variety of memory tasks (including story and event recall) and is displayed by children with cognitive impairments in addition to typically-developing children (Howe, 1991; La Rooy, Pipe, \& Murray, 2005; Winters \& Semchuk, 1986).

Even when reminisced details do not explicitly contradict earlier testimony, legal professionals often use changes in testimonial content to challenge the reliability and credibility of witnesses' reports (Brewer, Potter, Fisher, Bond, \& Luszcz, 1999). Arguments such as "If the story has changed, how do we know which one to believe?", "If this later account is true, then why didn't the child say this in the first place?", and "The story keeps changing, so how do we know what to believe?" can cast doubt on a child's testimony. Sometimes, inconsistencies lead 
to calls for the entire content of testimonies to be questioned (Fisher, Brewer, \& Mitchell, 2009).

Such arguments have some apparent surface logic and can be made without recourse to scientific theory about the workings of human memory: Triers of fact are simply urged to view new information with suspicion.

This legal tactic dovetails with concerns about the accuracy of later retellings that some psychologists have raised based on early research on false memories and suggestibility (Brainerd \& Poole, 1997, and La Rooy et al. 2009). To replicate practices from high-profile cases, in some studies children were repeatedly interviewed in a suggestive manner (for reviews, see Ceci \& Bruck, 1995; Ceci, Kulkofsky, Klemfuss, Sweeney, \& Bruck, 2007). Because increasing numbers of children fell foul of suggestions as interviews mounted (e.g., Ceci, Loftus, Leichtman, \& Bruck, 1994; Powell, Jones, \& Campbell, 2003), a perception emerged that the practice of conducting multiple interviews was inherently suggestive and should be avoided (as reflected in professional guidelines; e.g., Home Office, 2007; Ministry of Justice, 2011; Scottish Executive, 2007, 2011). This perception has persisted despite clear evidence that repeated suggestive interviews significantly degrade testimony — not repeated interviews per se (Goodman \& Quas, 2008; La Rooy et al., 2009; Poole \& White, 1995).

But there are still reasons to worry about information added in later interviews, when the passage of time and other factors may have weakened memory for the event. As the delay between repeated interviews lengthened in laboratory studies, the amount of correct information recalled often decreased, errors increased (Jones \& Pipe, 2002; Pipe, Sutherland, Webster, Jones, \& La Rooy, 2004), and thus the accuracy of the new information gained by conducting another interview decreased (La Rooy et al., 2007; Peterson, Moores \& White, 2001; Pipe, Gee, Wilson, \& Egerton, 1999, Salmon \& Pipe, 1997, 2000; Steward et al., 1996). For example, in a series of 
experiments examining children's memory for a pirate show (La Rooy et al., 2005), researchers manipulated the delay between repeated interviews and found that when repeated interviews were conducted within 24 hours of the event, new information was 92\% accurate (Experiment 1). When closely spaced repeated interviews were conducted after a 6-month delay, the accuracy of new information was 67\% (Experiment 2) and 72\% (Experiment 3). However, when repeated interviews were separated by a 6-month delay the accuracy was 56\% (Experiment 3 ), which is consistent with other studies examining long delays between repeated interviews (Salmon \& Pipe, 1997, 2000).

This clear pattern regarding length of the delay between interviews does not, however, mean that children communicate thoughtlessly or perform at chance levels when there is a long delay between retellings. Investigators still need to pay close attention to the new information provided by children and determine its relevance. In a unique case study in which a young girl witnessed the night-time abduction of her older sister, critical new details only emerged after the $5^{\text {th }}$ interview, which took place many months after the first (Orbach, Lamb, La Rooy, \& Pipe, 2012). Despite some inconsistencies in the witness's account across the repeated interviews, she nonetheless "suddenly" remembered the identity of the suspect and was able to communicate this to investigators. Consistent with this case study and findings from experimental paradigms, several field studies have documented that children participating in real forensic interviews across a variety of different case contexts produced new information as a result of additional interviews (Cederborg, La Rooy, \& Lamb, 2008; Hershkowitz \& Terner, 2007; Waterhouse, Ridley, Bull, La Rooy, \& Wilcock, 2016).

When researchers closely examined the details reported across repeated interviews, it became clear that a nuanced understanding is required to understand inconsistencies in children's 
reports (Gilbert \& Fisher, 2006; La Rooy et al., 2009). New information can take several forms: It may contain information that was not provided before in any form, an elaboration on previously recalled information, or a contradiction of previously recalled information. In field and case studies, elaborations of previously recalled information and completely new information were indeed quite common, whereas blatant contradictions in testimony were rare (Cederborg et al., 2008; La Rooy, Katz, Malloy, \& Lamb, 2010).

Research on reminiscence has clear implications for interviewers and evaluators. Because reminiscence often occurs when relaxed witnesses follow their own trains of thought, interviewers who conduct additional conversations should continue to follow guidelines for first time interviews that encourage building rapport and privileging open-ended prompts (Poole, 2016). When subsequent interviews have been conducted in a neutral manner, professionals who analyse interview transcripts should expect some added (but not contradictory or fantastic) details with each additional interview.

\section{Children Who Witnessed the Same Event Will Recall It Differently}

Many forensic cases involve several children who witnessed the same event, such as when siblings viewed an incident of domestic violence that they later described in interviews. From the outset of investigations through cases going to court, professionals often scrutinize the similarity of the accounts provided by different witnesses. What captures their attention are inconsistencies between accounts, either when details reported by one witness are not reported by another or when witnesses present competing accounts.

Researchers who study children's testimony expect some variability across event narratives - although they rarely analyze or report a finding that, to them, seems obvious. Instead, they usually aggregate children's accounts to summarize the completeness and accuracy 
of reports as a function of age, interview condition, and other variables (e.g., Butler, Gross, \& Hayne, 1995; Jones \& Pipe, 2002; Murachver, Pipe, Gordon, Owens, \& Fivush, 1996).

Unfortunately, these aggregated findings do not convey how much consistency researchers find in the narratives of children who witnessed the same event.

Interview transcripts from two studies illustrate how different children's accounts of the same event can be (La Rooy et al., 2005; Poole \& Dickinson, 2011). Two features characterize these transcripts: The children reported different details, yet there is always the sense that they are talking about the same event. Consider the example in Table 2. These children visited a friendly pirate and engaged in a 15-minute interaction that included making a treasure map, hoisting a sail, and feeding the pirate's parrot. Central to the activity was the goal of finding a treasure. Assistants conducted interviews immediately after this event, when details of the experience were still fresh in the children's minds. The narratives in Table 2 illustrate what children said when interviewers simply invited them to explain what had happened. Notice that the plot is very similar across narratives (finding treasure) even though each child's description is unique. Moreover, Child A reported considerably more details than Child B.

To illustrate the extent of this variability across narratives, consider transcripts from the five 7-year-olds, all assigned to the same interview condition for a delayed interview, who were touched by research assistants before and after a set of science demonstrations (Poole \& Dickinson, 2011). The question for this analysis was how many of these same-aged children reported overlapping activities, from a set of six possible activities, during open-ended prompting immediately after the events. Remarkably, only one activity was mentioned by every child, one was mentioned by four, one was mentioned by three, and two were mentioned only by a single child. Despite the tightly scripted nature of the events and subsequent interviews, each 
of the five children reported a unique collection of activities.

The conditions for these examples were optimal for facilitating consistent accounts of what happened because children experienced the same sequences of events - and their interviews were nonsuggestive. In real life, however, many factors might produce even greater inconsistencies across accounts, such as the fact that children often witness events from different physical or emotional perspectives. Add to these the differences among witnesses in cognitive and linguistic abilities, along with the varied questions posed by adults, and the result is certain to be different accounts of the same event by different witnesses.

Although contradictions that affect the overall plot of accounts should be rare when cowitnesses are interviewed under optimal conditions for recall, inconsistencies between witnesses can easily be elicited during cross-examination, which offers less-than-optimal conditions for retrieving accurate memories (Andrews \& Lamb, 2016; Myers, 1987). Witnesses might try to answer questions that seem fair or easy to answer on the surface but are actually very difficult to understand or nearly impossible to answer without guessing. The "tricky question" tactic involves asking witnesses numerous difficult-to-answer questions during cross-examination while, at the same time, pressuring them to be co-operative with their questioners.

Professionals who analyze testimony should ask whether accounts across witnesses preserve the overall plot of an event or whether children's collective accounts contain numerous unexpected contradictions. Although co-witness agreement does not guarantee that the events were witnessed (especially if witnesses possibly had access to a shared source of misinformation), comparing the content of testimonies from multiple witnesses can help decision-makings develop and test hypotheses about the origin of allegations.

\section{Event Narratives Can Get Better and Worse Over Time}


Because most memories fade over time, it is widely assumed that the totality of an event report should degrade as time passes. Studies of memories for medical emergencies have allowed researchers to evaluate this assumption for events that were highly stressful for most children. Regarding accuracy, it is indeed the case that children's accounts of their injury experiences deteriorated over time (Peterson, 1999, 2015; Peterson \& Whalen, 2001). However, this deterioration was surprisingly minimal, even over a delay that spanned a decade and even among children who had initially been quite young. For example, children who were between 3 and 5 years of age at the time of injury had accuracy rates of $91 \%$ for information provided about their injuries during an initial interview, and accuracy rates averaged an impressive $85 \%$ a decade later. Also surprising is that the drop in accuracy over time was unrelated to how many times the children had been previously interviewed, even though some had only one or two prior interviews whereas others had as many as five.

But accuracy is not the only property of an event report (Peterson, 2011): Another is completeness, which is the extent to which children recall such features as who was there, where it took place, when it happened, what objects were involved, what actions were taken by the child before and after the injury occurred, how adults responded, and so on. A short report that provides information about only a few of these features may be just as accurate as a longer report that includes information about considerably more features, but the latter report would be forensically more useful. Remarkably, the completeness of children's injury reports did not vary over time except among one group: The reports of children who were only 2 years old at the time of their initial interview became more complete as they got older. This improvement is probably an artifact of the difficulty of interviewing 2-year-olds - that is, in later interviews these children were older and more cooperative. 
A third property of event reports is the amount of elaboration (Peterson, 2011). Compare the following two excerpts from interviews of a child who lacerated his chin at age 4 . These excerpts were from the initial portion of his interviews:

Initial interview:

Experimenter: Tell me about what happened when you hurt your chin.

Child: Um ... I bumped it on my friend's swing set.

Experimenter: You bumped it on your friend's swing set.

Child: Yeah.

Experimenter: Yeah, uh-huh. What else happened?

Child: Ah, ah, is a (inaudible) one, you know, the the wrappers go on up there.

(Mom: "pressure treated one"- - that's what he's saying)

Experimenter: Okay.

Child: And and and there's wet footsteps there.

Experimenter: Oh, it was wet.

Child: And, and, and, and you bumped one r, r, r, right on it.

Experimenter: Oh no, and you bumped it on it. And what else?

Child: I had to go to the Janeway (hospital).

10-year follow-up interview:

Experimenter: Do you remember an injury you had when you were younger that you got interviewed about before? Yes? Okay so can you tell me anything that you remember about that?

Child: Um, it was during the summer and I'm pretty sure it was a nice day out, I'm pretty sure it was sunny. 
Experimenter: Mm-hmm.

Child: And we were down in Mark's back yard, down behind his house. Experimenter: Mm-hmm.

Child: And he had a like a play set, I don't know what you'd call it, like a jungle gym. And it had like swings on one side to the right and it had kinda like a tree house but not in a tree. But it was made of wood and it had one part where you could climb up with a rope and it had like blue handles almost.

Experimenter: Okay.

Child: And I think it was me and Mark, maybe it was Andy and a couple other kids, but I know it was more than just me there, and I went to, like, I was climbing up the rope, and my foot slipped, and I split my chin open on one of the blue pieces. Experimenter. Okay.

Child: And I remember I think my mom came down and she looked at it and she said that I had to go to the hospital.

Although the gist is the same in these two reports, the second is more informative. In injury studies, preschoolers provided about $20 \%$ more elaborative detail a decade later. This is probably due to children's larger vocabularies and better verbal skills, greater ability to fill in missing details by making accurate inferences, as well as greater understanding that — from an interviewer's perspective-more information is better. Thus, this property of event reports became better over time.

Overall, whether we should expect an account to be worse, unchanged, or better depends on what property of the account we are evaluating and the child's age during the initial interview. These findings explain why interviewers should persist with open-ended prompts 
even if children have been previously interviewed or the event occurred a long time ago.

Relatedly, although new information could be the product of suggestive influences, decisionmakers should not automatically assume that children are confabulating whenever later reports contain age-appropriate descriptions that were missing from earlier reports. (Also see Children Recall New Information in Subsequent Interviews in this review.)

\section{False Narratives Can Be Detailed and Coherent}

In addition to minor errors in otherwise accurate reports, children's narratives sometimes contain longer descriptions of fictitious happenings. False narratives can be detailed and coherent, and either convincing or implausible. They are easy to spot in laboratory studies because target events are known. In case material, false narratives are evident when children describe highly unlikely or impossible events (e.g., seeing witches fly; Ceci \& Bruck, 1995; Schreiber et al., 2006) or integrate information from well-known sources into narratives (e.g., plots of popular children's books). A range of memory phenomena generate false narratives, including suggestibility, source misattribution, and confabulation (for reviews see Johnson et al., 1993; Otgaar \& Howe, 2018; Poole et al., 2014).

Concern about false information stemming from suggestibility was the chief focus of early research on children's testimony. Studies that mimicked features of institutional abuse investigations documented that heavy-handed interviewing techniques could lead children to make coherent and detailed false reports (Ceci, Huffman, Smith, \& Loftus, 1994; Leichman \& Ceci, 1995), and subsequent studies found that even mild suggestions delivered through conversations with peers or parents could produce convincing but false descriptions of events (Principe \& Schindewolf, 2012; Poole \& Lindsay, 2001). Consider, for example, the following conversation between a parent and her 7-year old son about a laboratory visit that was arranged 
for a pilot study (provided by Jason Dickinson). Two weeks after the child participated in four science demonstrations about germs, his mother twice read him a story that described experienced and non-experienced demonstrations. This is how his mother, who was naive to what he actually experienced, later questioned him about the visit:

Parent: Do you remember when you went to the university and you met Mr. Science?

Child: Uh-huh.

Parent Can you tell me what happened? What did you guys talk about?

Child: Germs, like, um, we had to wash our hands so we didn't get germs, and then we watched a video about germs and what they could do.

Parent So, what else happened?

Child: We um, we also, oh we also, um, we also um, uh actually before that we got um, we got a microscope, and we looked at glitter and water.

Parent: So you mixed up glue and water?

Child: Uh-huh.

Parent: And then you look-used the microscope to take a look at it?

Child Yeah.

Parent Did Mr. Science say anything to you about that?

Child: Well he said, like, you always have to wash your hands.

Parent: Okay, did he tell you that before you started looking in the microscope or afterwards?

Child: Um, I think before.

Parent: Okay, after you looked in the microscope, what else did you do?

Child: I also got to, I also got to mix, I had to mix, um, the glue and the glitter up. 
This excerpt reveals three ways false narratives can develop. First, the child never washed his hands, nor was it suggested that he had. Rather, this account likely reflects reliance on gist-based memory (washing hands is conceptually associated with germs), which is a type of memory that can survive longer than verbatim-based memories (memories mirroring perceptual characteristics of the actual event; Brainerd \& Reyna, 1990; Brainerd \& Poole, 1997). Second, the child's account of looking through a microscope is false: This event was suggested in the misleading book. Third, the child said he "looked at glitter and water," but his mother recast this by saying "mixed up glue and water." After the mother injected inaccurate details into the conversation, the child later repeated them. This pattern of adults distorting responses, and children incorporating the distortions into conversation, has been documented in forensic interviews as well (Roberts \& Lamb, 1999; for laboratory findings on children's compliance with distortions, see Hunt \& Borgida, 2001).

Young children who err in their narratives are rarely accused of intentionally trying to deceive adults, but deception motivated by self-preservation (to avoid negative consequences for oneself) does develop in early childhood (Evans \& Lee, 2013; Fu, Sai, Yuan, \& Lee, 2018). Therefore, lying can be a plausible hypothesis for some allegations, even among young children. Coinciding with developmental gains in executive function (e.g., theory of mind, sourcemonitoring), as children mature their lies grow more sophisticated and reflect increasingly complex motivations (e.g., the desire to protect a loved one; Heyman, 2014; Williams, Moore, Crossman, \& Talwar, 2016).

Like confabulations, deceptive statements can be detailed and coherent, but is their form and content measurably different than truthful statements? Although some studies have found statistically significant differences between true and false statements on a variety of criteria, 
there is wide variability in accuracy rates for classifying true and false accounts (Brunet et al., 2013; Roma, Martini, Sabatello, Tatarelli, \& Ferracuti, 2011; Vrij, 2005; Welle, Berclaz, Lacasa, $\&$ Niveau, 2016). The different pictures painted by mean differences and classification accuracy are clear from a meta-analysis of experimental studies that compared the presence of CriterionBased Content Analysis (CBCA) characteristics (e.g., quantity of details, description of unexpected complications during the incident) in true and fictitious reports: Although there was a moderate effect size, with experienced accounts containing more criteria, only $64 \%$ of true reports were accurately classified (Amado, Arce, \& Fariña, 2015).

Field studies of confirmed and unconfirmed sexual abuse cases have evaluated the content of children's narratives when unconfirmed cases represented an unknown mixture of intentional lies, true but miscategorized reports, and false reports stemming from other mechanisms. Results based on CBCA criteria have ranged from highly concerning (no evidence the technique reliably identifies false allegations; Welle et al., 2016) to optimistic (Roma et al., 2011). A meta-analysis found that about $90 \%$ of statements deemed truthful were correctly classified across studies (Amado et al., 2015), but there are also many criteria in narratives from implausible cases - even when investigators used rigorous procedures for categorizing allegations as false (Lamb, Sternberg, Esplin, Hershkowitz, Orbach, \& Hovav, 1997). This finding led Lamb et al. (1997) to warn practitioners against "incautious application" (p. 261) of content analysis in forensic settings.

It has proven challenging to devise a procedure that reliably separates truthful from deceptive accounts because narrative content is heavily influenced by age (Buck, Warren, Betman, \& Brigham, 2002), witnesses’ intelligence and social skills (Vrij, 2005), the familiarity of target events (Blandon-Gitlin, Pezdek, Rogers, \& Brodie, 2005), whether events were 
experienced once or were repeated (Connolly \& Lavoie, 2015), and interviewers' skill (Lamb, 1998). As a result, it is not surprising that adults' ability to classify children's reports hovers around chance, regardless of whether children spontaneously invented lies, generated their own details for coached lies, or received more extensive coaching from adults (Gongola, Scurich, \& Quas, 2017).

In sum, evaluating the reliability of children's testimony is challenging because false narratives can be the product of multiple mechanisms beyond the control of investigators: In addition to parroting suggestions, children are capable of spontaneously generating false details and erroneously interweaving information from multiple sources into their accounts. As a result, their false narratives can be as long as (Poole \& Lindsay, 2001, supplementary report) or longer than (Bruck, Ceci, \& Hembrooke, 2002) true narratives, and other characteristics, such as the presence of emotional terms and temporal connectivity, do not always distinguish fact from fiction (Bruck et al., 2002). But despite the fact that children's accounts sometimes contain convincing falsehoods, eliciting detailed narratives with nonleading invitations is still the best strategy for learning what children experienced, and planning questions that test alternative hypotheses for allegations is the best way to support the overall investigation (see State of Michigan Governor's Task Force on Child Abuse and Neglect and Department of Health and Human Services, 2017, for example questions). Because children's event narratives are rarely literal reproductions of events, professionals who evaluate cases must document whether, in light of the principles we described here, there is a plausible and coherent story that is unlikely to have stemmed from outside influences. To make these determinations, professionals should consider children's levels of cognitive maturity and language proficiency, how case features and interviewers' skills might have impacted their memory reports, and the social contexts of their 
lives.

\section{Conclusion}

Children provide testimony in a variety of circumstances: as victims or suspected victims of maltreatment; as witnesses in criminal, civil, and family court proceedings; and as suspected perpetrators of crimes. Each type of case has unique dynamics that impact children's abilities to participate in conversations and the type of information that is critical for effective decisionmaking by the adults who investigate and interpret their testimonies. In this review, we summarized fifteen principles of how children talk about events that transcend these different contexts. The principles are relevant across settings because they reflect foundational developmental and cognitive realities, such as how children use language and search memory. These principles are not unique to the transcript sets we reviewed, nor is it the case that further principles would not arise from these or other transcript sets. Although they do not capture all the phenomena that occur in real-world interviews (where adults' cognitions and biases interact in numerous ways with children's minds), we elected to focus on phenomena that occur frequently and even when interviews are generally well-conducted.

As the fifteen principles illustrate, transcripts from laboratory and field studies can provide rich insight into how children talk about events, and the ability to attach supplementary materials to online articles opens new possibilities for researchers to describe their data more fully. For example, transcript excerpts illustrating typical responses from children of various ages, along with excerpts illustrating variability around mean values, would give professionals a better sense of how children respond to the types of questions that populate interviews. And when researchers spot interesting phenomena that are unrelated to their studies' main purposes, sharing these observations could improve understanding of children's testimony while also 
generating questions for future research. Moving forward, we encourage authors to think beyond the statistics we use to test research questions and also present discussions and examples that will cultivate greater understanding of how children reveal their lives in interviews. 


\section{References}

Alexander, K. W., Goodman, G. S, Schaaf, J. M., Edelstein, R. S., Quas, J. A., \& Shaver, P. R. (2002). The role of attachment and cognitive inhibition in children's memory and suggestibility for a stressful event. Journal of Experimental Child Psychology, 83, 262290. doi: 10.1016/S0022-0965(02)00149-2

Amado, B. G., Arce, R., \& Fariña, F. (2015). Undeutsch hypothesis and Criteria Based Content Analysis: A meta-analytic review. European Journal of Psychology Applied to Legal Context, 7, 3-12. doi: 10.1016/j.ejpal.2014.11.002

Andrews, S. J. \& Lamb, M. E. (2016). How do lawyers examine and cross-examine children in Scotland? Applied Cognitive Psychology, 30, 953-971. doi: 10.1002/acp.3286

Bauer, P. J. (2015). A complementary processes account of the development of childhood amnesia and a personal past. Psychological Review, 122, 204-231. doi:

10.1037/a0038939

Bauer, P. J., Kroupina, M. G., Schwade, J. A., Dropik, P. L., \& Wewerka, S. S. (1998). If memory serves, will language? Later verbal accessibility of early memories. Development and Psychopathology, 10, 655-679. doi: 10.1017/S0954579498001801

Benson, M. S., \& Powell, M. B. (2015). Evaluation of a comprehensive interactive training system for investigative interviewers of children. Psychology, Public Policy, and Law, 21, 309-322. doi: 10.1037/law0000052

Blandon-Gitlin, I., Pezdek, K., Rogers, M., \& Brodie, L. (2005). Detecting deception in children: An experimental study of the effect of event familiarity on CBCA ratings. Law and Human Behavior, 29, 187-197. doi: 10.1007/s10979-005-2417-8

Brainerd, C. J., \& Poole, D. A. (1997). Long-term survival of children's false memories: A 
review. Learning and Individual Differences, 9, 125-151. doi: 10.1016/S10416080(97)90003-0

Brainerd, C. J., \& Reyna, V. F. (1990). Gist is the grist: Fuzzy-trace theory and the new intuitionism. Developmental Review, 10, 3-47. doi: 10.1016/0273-2297(90)90003-M

Brewer, N., Potter, R., Fisher, R. P., Bond, N., \& Luszcz, M. A. (1999). Beliefs and data on the relationship between consistency and accuracy of eyewitness testimony. Applied Cognitive Psychology, 13, 297-313. doi: 10.1002/(SICI)10990720(199908)13:4<297::AID-ACP578>3.0.CO;2-S

Broaders, S. C., \& Goldin-Meadow, S. (2010). Truth is at hand: How gesture adds information during investigative interviews. Psychological Science, 21, 623-628. doi: $10.1177 / 0956797610366082$

Brubacher, S. P., Earhart, B., Roberts, K. P., \& Powell, M. B. (2018). Effects of label training and recall order on children's reports of a repeated event. Applied Cognitive Psychology. Advance online publication. doi: 10.1002/acp.3440

Brubacher, S. P., Glisic, U., Roberts, K. P., \& Powell, M. B. (2011). Children's ability to recall unique aspects of one occurrence of a repeated event. Applied Cognitive Psychology, 25, 351-358. doi: 10.1002/acp.1696

Brubacher, S. P., Malloy, L. C., Lamb, M. E., \& Roberts, K. P. (2013). How do interviewers and children discuss individual occurrences of alleged repeated abuse in forensic interviews? Applied Cognitive Psychology, 27, 443-450. doi: 10.1002/acp.2920

Brubacher, S. P., Poole, D. A., \& Dickinson, J. J. (2015). The use of ground rules in interviews with children: A synthesis and call for research. Developmental Review, 36, 15-33. doi: 10.1016/j.dr.2015.01.001 
Brubacher, S. P., Powell, M. B., \& Roberts, K. P. (2014). Recommendations for interviewing children about repeated experiences. Psychology, Public Policy, \& Law, 20, 325-335. doi: $10.1037 /$ law0000011

Brubacher, S. P., Roberts, K. P., \& Powell, M. B. (2011). Effects of practicing episodic versus scripted recall on children's subsequent narratives of a repeated event. Psychology, Public Policy, and Law, 17, 286-314. doi: 10.1037/a0022793

Brubacher, S. P., Roberts, K. P., \& Powell, M. B. (2012). Retrieval of episodic versus generic information: Does the order of recall affect the amount and accuracy of details reported by children about repeated events? Developmental Psychology, 48, 111-122. doi:10.1037/a0025864

Bruck, M., Ceci, S. J., \& Hembrooke, H. (2002). The nature of children's true and false narratives. Developmental Review, 22, 520-554. doi: 10.1016/S0273-2297(02)00006-0

Brunet, M. K., Evans, A. D., Talwar, V., Bala, N., Lindsay, R. C. L., \& Lee, K. (2013). How children report true and fabricated stressful and non-stressful events. Psychiatry, Psychology and Law, 20, 867-881. doi: 10.1080/13218719.2012.750896

Buck, J. A., Warren, A. R., Betman, S. I., \& Brigham, J. C. (2002). Age differences in CriteriaBased Content Analysis scores in typical child sexual abuse interviews. Journal of Applied Developmental Psychology, 23, 267-283. doi: 10.1016/S0193-3973(02)00107-7

Butler, S., Gross, J., \& Hayne, H. (1995). The effect of drawing on memory performance in young children. Developmental Psychology, 31, 597-608. doi: 10.1037/00121649.31.4.597

Ceci, S. J., \& Bruck, M. (1995). Jeopardy in the courtroom: A scientific analysis of children's testimony. Washington, DC: American Psychological Association. 
Ceci, S. J., Huffman, M. L. C., Smith, E., \& Loftus, E. F. (1994). Repeatedly thinking about a non-event: Source misattributions among preschoolers. Consciousness and Cognition, 3, 388-407. doi: 10.1006/cog.1994.1022

Ceci, S. J., Kulkofsky, S., Klemfuss, J. Z., Sweeney, C. D., \& Bruck, M. (2007). Unwarranted assumptions about children's testimonial accuracy. Annual Review of Clinical Psychology, 3, 311-328. doi: 10.1146/annurev.clinpsy.3.022806.091354

Ceci, S. J., Loftus, E. F., Leichtman, M. D., \& Bruck, M. (1994). The possible role of source misattributions in the creation of false beliefs among preschoolers. International Journal of Clinical and Experimental Hypnosis, 42, 304-320. doi: 10.1080/00207149408409361

Cederborg, A.-C., La Rooy, D., \& Lamb, M. (2008). Repeated interviews with children who have intellectual disabilities. Journal of Applied Research in Intellectual Disabilities, 21, 103-113. doi: 10.1111/j.1468-3148.2007.00372.x

Cederborg, A.-C., \& Lamb, M. E. (2008). The need for systematic and intensive training of forensic interviewers. In T. I. Richardson \& M. V. Williams (Eds.), Child abuse and violence (pp. 1-17). Hauppauge, NY: Nova Science Publishers.

Connolly, D. A., \& Gordon, H. M. (2014). Can order of general and specific memory prompts help children to recall an instance of a repeated event that was different from the others? Psychology, Crime, \& Law, 20, 852-864.

Connolly, D. A., \& Lavoie, J. A. A. (2015). Discriminating veracity between children's reports of single, repeated, and fabricated events: A critical analysis of Criteria-Based Content Analysis. American Journal of Forensic Psychology, 33, 25-48.

Danby, M. C., Brubacher, S. P., Sharman, S. J., Powell, M. B., \& Roberts, K. P. (2017). Children's reasoning about which episode of a repeated event is best remembered. 
Applied Cognitive Psychology, 31, 99-108. doi: 10.1002/acp.3306

Danby, M., Sharman, S., Brubacher, S. P., Powell, M. B., \& Roberts, K. P. (2017). Differential effects of general versus cued invitations on children's reports of a repeated event. Psychology, Crime, \& Law, 23, 794-811. doi: 10.1080/1068316X.2017.1324028

Devitt, A. L., Monk-Fromont, E., Schacter, D. L., \& Addis, D. R. (2016). Factors that influence the generation of autobiographical memory conjunction errors. Memory, 24, 204-222. doi: $10.1080 / 09658211.2014 .998680$

Evans, A. D., \& Lee, K. (2013). Emergence of lying in very young children. Developmental Psychology, 49, 1958-1963. doi: 10.1037/a0031409

Feltis, B. B., Powell, M. B., \& Roberts, K. P. (2011). The effect of event repetition on the production of story grammar in children's event narratives. Child Abuse \& Neglect, 35, 180-187. doi: 10.1016/j.chiabu.2010.11.004

Feltis, B. B., Powell, M. B., Snow, P. C., \& Hughes-Scholes, C. H. (2010). An examination of the association between interviewer question type and story-grammar detail in child witness interviews about abuse. Child Abuse \& Neglect, 34, 407-413. doi:

10.1016/j.chiabu.2009.09.019

Fiestas, C. E., Bedore, L. M., Peña, E. D., \& Nagy, V. J. (2005). Use of mazes in the narrative language samples of bilingual and monolingual 4- to 7-year old children. Proceedings of the 4th International Symposium on Bilingualism. Somerville, MA: Cascadilla Press. Retrieved from http://www.lingref.com/isb/4/057ISB4.PDF

Fisher, R. P., Brewer, N., \& Mitchell, G. (2009). The relation between consistency and accuracy of eyewitness testimony: Legal versus cognitive explanations. In R. Bull, T. Valentine, \& T. Williamson (Eds.), Handbook of psychology of investigative interviewing: Current 
developments and future directions (pp. 121-136). West Sussex, UK: Wiley-Blackwell. doi: 10.1002/9780470747599.ch8

Foley, M. A. (2014). Children's memory for source. In P. J. Bauer \& R. Fivush (Eds.), The Wiley handbook on the development of children's memory (Vol. 1, pp. 427-452). Chichester, UK: Wiley. doi: 10.1002/9781118597705.ch19

Fu, G., Sai, L., Yuan, F., \& Lee, K. (2018). Young children's self benefiting lies and their relation to executive functioning and theory of mind. Infant and Child Development, 27. Advance online publication.

Gilbert, J. A. E., \& Fisher, R. P. (2006). The effects of varied retrieval cues on reminiscence in eyewitness memory. Applied Cognitive Psychology, 20, 723-739. doi: 10.1002/acp.1232

Gongola, J., Scurich, N., \& Quas, J. A. (2017). Detecting deception in children: A meta-analysis. Law and Human Behavior, 41, 44-54. doi: 10.1037/lhb0000211

Goodman, G. S., Ogle, C. M., McWilliams, K., Narr, R. K., \& Paz-Alonso, P. (2014). Memory development in the forensic context. In P. J. Bauer \& R. Fivush (Eds.), The Wiley handbook on the development of children's memory (Vol. 2, pp. 920-941). Chichester, UK: Wiley. doi: 10.1002/9781118597705.ch39

Goodman, G. S., \& Reed, R. S. (1986). Age differences in eyewitness testimony. Law and Human Behavior, 10, 317-332. doi: 10.1007/BF01047344

Goodman, G. S., \& Quas, J. A. (2008). Repeated interviews and children's memory: It's more than just how many. Current Directions in Psychological Science, 17, 386-390. doi: 10.1111/j.1467-8721.2008.00611.x

Goodman, G. S., Quas, J. A., Batterman-Faunce, J. M., Riddlesberger, M. M., \& Kuhn, J. (1994). Predictors of accurate and inaccurate memories of traumatic events experienced in 
childhood. Consciousness and Cognition, 3, 269-294.

Gotzke, C., \& Gosse, H. S. (2009). Interacting (37 - 60 months) - increasingly social communicators. In the Canadian Language and Literacy Research Network (2009), Handbook of language and literacy development: A roadmap from 0 to 60 months. Retrieved from http://www.theroadmap.ualberta.ca/interactions/research/37-60

Grant, J. B., \& Suddendorf, T. (2011). Production of temporal terms by 3-, 4-, and 5-year-old children. Early Childhood Research Quarterly, 26, 87-95. doi: 10.1016/j.ecresq.2010.05.002

Heritage, J., Robinson, J. D., Elliott, M. N., Beckett, M., \& Wilkes, M. (2007) Reducing patients' unmet concerns in primary care: The difference one word can make. Journal of General Internal Medicine, 22, 1429-1433. doi: 10.1007\%2Fs11606-007-0279-0

Hershkowitz, I., \& Terner, A. (2007). The effects of repeated interviewing on children's forensic statements of sexual abuse. Applied Cognitive Psychology, 21, 1131-1143. doi: 10.1002/acp.1319

Heyman, G. D. (2014). Children's reasoning about deception: A cross-cultural perspective. In E. J. Robinson \& S. Einav (Eds.), Trust and skepticism: Children's selective learning from testimony. (pp. 83-94). New York, NY: Psychology Press.

Home Office. (2007). Achieving best evidence in criminal proceedings: Guidance on interviewing victims and witnesses, and using special measures. London, England: Author.

Howe, M. L. (1991). Misleading children's story recall: Forgetting and reminiscence of the facts. Developmental Psychology, 27, 746-762. doi: 10.1037/0012-1649.27.5.746

Hudson, J. A., Fivush, R., \& Kuebli, J. (1992). Scripts and episodes: The development of event 
memory. Applied Cognitive Psychology, 6, 483-505. doi: 10.1002/acp.2350060604

Hudson, J. A., \& Shapiro, L. R. (1991). From knowing to telling: The development of children's scripts, stories, and personal narratives. In A. McCabe \& C. Peterson (Eds.), Developing narrative structure (pp. 89-136). Hillsdale NJ: Lawrence Erlbaum.

Hunt, J. S., \& Borgida, E. (2001). Is that what I said? Witnesses' responses to interviewer modifications. Law \& Human Behavior, 25, 583-603. doi: 10.1023/A:1012754207074

Hutcheson, G. D., Baxter, J. S., Telfer, K., \& Warden, D. (1995). Child witness statement quality: Question type and errors of omission. Law and Human Behavior, 19, 631-648. doi: 10.1007/BF01499378

Johnson, M. K., Hashtroudi, S., \& Lindsay, D. S. (1993). Source monitoring. Psychological Bulletin, 114, 3-28. doi: 10.1037/0033-2909.114.1.3

Jones, C. H., \& Pipe, M.-E. (2002). How quickly do children forget events? A systematic study of children's event reports as a function of delay. Applied Cognitive Psychology, 16, 755768. doi: $10.1002 /$ acp. 826

Lamb, M. E. (1998). Assessments of children's credibility in forensic contexts. Current Directions in Psychological Science, 7, 43-46. doi 10.1111/1467-8721.ep13175602

Lamb, M. E., Brown, D. A., Hershkowitz, I., Orbach, I., \& Esplin, P. W. (2018). Tell me what happened: Questioning children about abuse (2nd ed.). Hoboken, NY: Wiley-Blackwell.

Lamb, M. E., Orbach, Y., Hershkowitz, I., Esplin, P. W., \& Horowitz, D. (2007). A structured forensic interview protocol improves the quality and informativeness of investigative interviews with children: A review of research using the NICHD Investigative Interview Protocol. Child Abuse \& Neglect, 31, 1201-1231. doi: 10.1016/j.chiabu.2007.03.021

Lamb, M. E., Sternberg, K. J., Orbach, Y., Esplin, P. W., Stewart, H., \& Mitchell, S. (2003). Age 
differences in young children's responses to open-ended invitations in the course of forensic interviews. Journal of Consulting and Clinical Psychology, 71, 926-934. doi: 10.1037/0022-006X.71.5.926

Lamb, M. E., Sternberg, K. J., Esplin, P. W., Hershkowitz, I., Orbach, Y., \& Hovav, M. (1997). Criterion-Based Content Analysis: A field validation study. Child Abuse \& Neglect, 21, 255-264. doi: 10.1016/S0145-2134(96)00170-6

La Rooy, D., Brubacher, S. P., Aromäki-Stratos, A., Cyr, M., Hershkowitz, I., Korkman, J., ... Lamb, M. E. (2015). The NICHD Protocol: A review of an internationally-used evidencebased tool for training child forensic interviewers. Journal of Criminological Research, Policy and Practice, 1, 76-89. doi: 10.1108/JCRPP-01-2015-0001

La Rooy D., Pipe, M.-E., \& Murray, J. E. (2007). Enhancing children's event recall after long delays. Applied Cognitive Psychology, 21, 1-17. doi: 10.1002/acp.1272

La Rooy,D., Katz, C., Malloy, L. C., \& Lamb, M. E. (2010). Do we need to rethink guidance on repeated interviews? Psychology, Public Policy, and Law, 16, 373-392. doi: $10.1037 / \mathrm{a} 0019909$

La Rooy, D., Lamb, M. E., \& Pipe, M.-E (2009). Repeated interviewing: A critical evaluation of the risks and potential benefits. In K. Kuehnle \& M. Connell (Eds.), The evaluation of child sexual abuse allegations: A comprehensive guide to assessment and testimony (pp. 327-361). Hoboken, NJ: John Wiley \& Sons.

La Rooy, D. L., Pipe, M.-E., \& Murray, J. E. (2005). Reminiscence and hypermnesia in children's eyewitness memory. Journal of Experimental Child Psychology, 90, 235-254. doi: 10.1016/j.jecp.2004.11.002

Langley, H. A., Coffman, J. L., \& Ornstein, P. A. (2017). The socialization of children's 
memory: Linking maternal conversational style to the development of children's autobiographical and deliberate memory skills. Journal of Cognition and Development, 18,63-86. doi: 10.1080/15248372.2015.1135800

Lee, J. K., Wendelken, C., Bunge, S. A., \& Ghetti, S. (2016). A time and place for everything: Developmental differences in the building blocks of episodic memory. Child Development, 87, 194-210. doi: 10.1111/cdev.12447

Leichtman, M. D., \& Ceci, S. J. (1995). The effects of stereotypes and suggestions on preschoolers' reports. Developmental Psychology, 31, 568-578. doi: 10.1037/00121649.31.4.568

Lloyd, M. E., Doydum, A. O., \& Newcombe, N. S. (2009). Memory binding in early childhood: Evidence for a retrieval deficit. Child Development, 80, 1321-1328. doi: 10.1111/j.14678624.2009.01353.x

Lyon, T. D. (2017). Investigative interviewing of the child. In D. Duquette, A. M. Haralambie, \& V. S. Sankaran (Eds.), Child welfare law and practice, $3^{\text {rd }}$ ed (pp. $\left.87-113\right)$. Denver, CO, USA: Bradford.

Lyon, T. D., Scurich, N., Choi, K., Handmaker, S., \& Blank, R. (2012). “How did you feel?”: Increasing child sexual abuse witnesses' production of evaluative information. Law \& Human Behavior, 36, 448-457. doi: 10.1037/h0093986

Madsen, H. B., \& Kim, J. H. (2016). Ontogeny of memory: An update on 40 years of work on infantile amnesia. Behavioural Brain Research, 298, 4-14. doi: 10.1016/j.bbr.2015.07.030

Ministry of Justice. (2011). Achieving best evidence in criminal proceedings: Guidance on interviewing victims and witnesses, and guidance on using special measures. London, 
England: Author.

Murachver, T., Pipe, M.-E., Gordon, R., Owens J. L., \& Fivush, R. (1996). Do, show, and tell:

Children's event memories acquired through direct experience, observation, and stories.

Child Development, 67, 3029-3044. doi: 10.1111/j.1467-8624.1996.tb01901.x

Myers, J. E. B. (1987). The child witness: Techniques for direct examination, cross-examination, and impeachment. Pacific Law Journal, 18, 801-942. Retrieved from https://scholarlycommons.pacific.edu/cgi/viewcontent.cgi?article=1071\&context=faculty articles

Nahum, L., Bouzerda-Wahlen, A., Guggisberg, A., Ptak, R., \& Schnider, A. (2012). Forms of confabulation: Dissociations and associations. Neuropsychologia, 50, 2524-2534. doi: 10.1016/j.neuropsychologia.2012.06.026

Newcombe, N. S., Lloyd, M. E., \& Balcomb, F. (2012). Contextualizing the development of recollection: Episodic memory and binding in young children. In S. Ghetti, \& P. J. Bauer (Eds.), Origins and development of recollection: Perspectives from psychology and neuroscience (pp. 73-100). New York, NY: Oxford University Press.

Newcombe, N. S., Lloyd, M. E., \& Ratliff, K. R. (2007). Development of episodic and autobiographical memory: A cognitive neuroscience perspective. In R. V. Kail (Ed.), Advances in child development and behavior: Vol. 35 (pp. 37-85). SanDiego, CA: Elsevier Academic Press.

Orbach, Y., Lamb, M. E., La Rooy, D., \& Pipe, M.-E. (2012). A case study of witness consistency and memory recovery across multiple investigative interviews. Applied Cognitive Psychology, 26, 118-129. doi: 10.1002/acp.1803

Otgaar, H., \& Howe, M. L. (2018). Finding the truth in the courtroom: Dealing with deception, 
lies, and memories. New York, NY: Oxford University Press.

Peterson, C. (1999). Children's memory for medical emergencies: 2 years later. Developmental Psychology, 35, 1493-1506. doi: 10.1037/0012-1649.35.6.1493

Peterson, C. (2011). Children's memory reports over time: Getting both better and worse. Journal of Experimental Child Psychology, 109, 275-293. doi: 10.1016/j.jecp.2011.01.009

Peterson, C. (2015). A decade later: Adolescents' memory for medical emergencies. Applied Cognitive Psychology, 29, 826-834. doi: 10.1002/acp.3192

Peterson, C., \& Bell, M. (1996). Children's memory for traumatic injury. Child Development, 67, 3045-3070. doi: 10.2307/1131766

Peterson, C., \& Biggs, M. (1997). Interviewing children about trauma: Problems with "specific" questions. Journal of Traumatic Stress, 10, 279-290. doi: 10.1023/A:1024882213462

Peterson, C., Dowden, C., \& Tobin, J. (1999). Interviewing preschoolers: Comparisons of yes/no and wh- questions. Law and Human Behavior, 23, 539-555. doi: 10.1023/A:1022396112719

Peterson, C., Grant, V. V., \& Boland, L. D. (2005). Childhood amnesia in children and adolescents: Their earliest memories. Memory, 13, 622-637. doi: $10.1080 / 09658210444000278$

Peterson, C., Hallett, D., \& Compton-Gillingham, C. (2017). Childhood amnesia in children: A prospective study across eight years. Child Development, 89, e520 - e534. doi: 10.1111/cdev.12972

Peterson, C., Moores, L., \& White, G. (2001). Recounting the same events again and again: Children's consistency across multiple interviews. Applied Cognitive Psychology, 15, 
353-371. doi: 10.1002/acp.708

Peterson, C., Morris, G., Baker-Ward, L., \& Flynn, S. (2014). Predicting which childhood memories persist: Contributions of memory characteristics. Developmental Psychology, 50, 439-448. doi: 10.1037/a0033221

Peterson, C., \& Parsons, B. (2005). Interviewing former 1- and 2-year olds about medical emergencies 5 years later. Law and Human Behavior, 29, 743-754. doi: 10.1007/s10979005-8378-0

Peterson, C., \& Rideout, R. (1998). Memory for medical emergencies experienced by 1- and 2year-olds. Developmental Psychology, 34, 1059-1072. doi: 10.1037/00121649.34.5.1059

Peterson, C., Wang, Q., \& Hou, Y. (2009). "When I was little": Childhood recollections in Chinese and European Canadian grade school children. Child Development, 80, 506-518. doi: $10.1111 / \mathrm{j} .1467-8624.2009 .01275 . \mathrm{x}$

Peterson, C., Warren, K. L., \& Short, M. M. (2011). Infantile amnesia across the years: A 2-year follow-up of children's earliest memories. Child Development, 82, 1092-1105. doi: 10.1111/j.1467-8624.2011.01597.x

Peterson, C., \& Whalen, N. (2001). Five years later: Children's memory for medical emergencies. Applied Cognitive Psychology, 15, S7-S24. doi: 10.1002/acp.832

Pipe, M.-E., Gee, S., Wilson, J. C., \& Egerton, J. M. (1999). Children's recall 1 or 2 years after an event. Developmental Psychology, 35, 781-789. doi: 10.1037/0012-1649.35.3.781

Pipe, M-E., Sutherland, R., Webster, N., Jones, C., \& La Rooy, D. (2004). Do early interviews affect children's long-term event recall? Applied Cognitive Psychology, 18, 823-839. doi: 10.1002/acp.1053 
Poole, D. A. (2016). Interviewing children: The science of conversation in forensic contexts. Washington, DC: American Psychological Association.

Poole, D. A., Brubacher, S. P., \& Dickinson, J. J. (2015). Children as witnesses. In B. L. Cutler \& P. A. Zapf (Eds.), APA handbook of forensic psychology (Vol. 2, pp. 3-31). Washington, DC: American Psychological Association.

Poole, D. A., \& Dickinson, J. J. (2011). Evidence supporting restrictions on uses of body diagrams in forensic interviews. Child Abuse \& Neglect, 35, 659-669. doi: 10.1016/j. chiabu.2011.05.004

Poole, D. A., \& Dickinson, J. J. (2014). Comfort drawing during investigative interviews: Evidence of the safety of a popular practice. Child Abuse \& Neglect, 38, 192-201. doi: 10.1016/j.chiabu.2013.04.012

Poole, D. A., Dickinson, J. J., \& Brubacher, S. P. (2014). Sources of unreliable testimony from children. Roger Williams University Law Review, 19, 382-410.

Poole, D. A., \& Lindsay, D. S. (2001). Children's eyewitness reports after exposure to misinformation from parents. Journal of Experimental Psychology: Applied, 7, 27-50. doi: 10.1037//1076-898X.7.1.27

Poole, D. A., \& White, L. T. (1993). Two years later: Effect of question repetition and retention interval on the eyewitness testimony of children and adults. Developmental Psychology, 29, 844-853. doi 10.1037//0012-1649.29.5.844

Poole, D. A., \& White, L. T. (1995). Tell me again and again: Stability and change in the repeated testimonies of children and adults. In M. S. Zaragoza, J. R. Graham, G. C. N. Hall, R. Hirschman, \& Y. S. Ben-Porath (Eds.), Memory and testimony in the child witness (pp. 24-43). Thousand Oaks, CA: Sage. 
Powell, M. B., Jones, C. H., \& Campbell, C. (2003). A comparison of preschoolers' recall of experienced versus non-experienced events across multiple interviews. Applied Cognitive Psychology, 17, 935-952. doi: 10.1002/acp.932

Price, H. L., Connolly, D. A., \& Gordon, H. M. (2016). Children who experienced a repeated event only appear less accurate in a second interview than those who experienced a unique event. Law and Human Behavior, 40, 362-373. doi: 10.1037/lhb0000194

Principe, G. F., \& Schindewolf, E. (2012). Natural conversations as a source of false memories in children: Implications for the testimony of young witnesses. Developmental Review, 32, 205-223. doi: 0.1016/j.dr.2012.06.003

Reese, E., \& Robertson, S. J. (2019). Origins of adolescents' earliest memories. Memory, 27, 7991. doi: 10.1080/09658211.2018.1512631

Reyna, V. F., \& Brainerd, C. J. (2011). Dual processes in decision making and developmental neuroscience: A fuzzy-trace model. Developmental Review, 31, 180-206. doi: 10.1016/j.dr.2011.07.004

Roberts, K. P., Brubacher, S. P., Powell, M. B., \& Price, H. L. (2011). Practice narratives. In M. E. Lamb, D. La Rooy, L. Malloy, \& C. Katz (Eds.), Children's testimony: A handbook of psychological research and forensic practice (2d ed., pp. 129-146). Chichester, UK: Wiley. doi: 10.1002/9781119998495.ch7

Roberts, K. P., \& Lamb, M. E. (1999). Children's responses when interviewers distort details during investigative interviews. Legal \& Criminological Psychology, 4, 23-31. doi $10.1348 / 135532599167752$

Roma, P., Martini, P. S., Sabatello, U., Tatarelli, R., \& Ferracuti, S. (2011). Validity of criteriabased content analysis (CBCA) at trial in free-narrative interviews. Child Abuse \& 
Neglect, 35, 613-620. doi: 10.1016/j.chiabu.2011.04.004

Rubin, D. C. (2000). The distribution of early childhood memories. Memory, 8, 265-269. doi: $10.1080 / 096582100406810$

Salmon, K., \& Pipe, M.-E. (1997). Props and children's event reports: The impact of a 1-year delay. Journal of Experimental Child Psychology, 65, 261-292. doi: 10.1006/jecp.1996.2362

Salmon, K., \& Pipe, M.-E. (2000). Recalling an event one year later: The impact of props, drawing and a prior interview. Applied Cognitive Psychology, 14, 99-120. doi: 10.1002/(SICI)1099-0720(200003/04)14:23.0

Salmon, K., \& Reese, E. (2016). The benefits of reminiscing with young children. Current Directions in Psychological Science, 25, 233-238. doi: 10.1177/0963721416655100

Saywitz, K. J., Lyon, T. D., \& Goodman, G. S. (2018). When interviewing children: A review and update. In B. Klika \& J. Conte \& (Eds.), APSAC handbook on child maltreatment $\left(4^{\text {th }}\right.$ ed., pp. 310-329). Newbury Park, CA: Sage.

Scarf, D., Gross, J., Colombo, M., \& Hayne, H. (2013). To have and to hold: Episodic memory in 3-and 4-year-old children. Developmental Psychobiology, 55, 125-132. doi: 10.1002/dev.21004

Schneider, L., Price, H. L., Roberts, K. P., \& Hedrick, A. M. (2011). Children's episodic and generic reports of alleged abuse. Applied Cognitive Psychology, 25, 862-870. doi: 10.1002/acp.1759

Schreiber, N., Bellah, L. D., Martinez, Y., McLaurin, K. A., Strok, R., Garven, S., \& Wood, J. M. (2006). Suggestive interviewing in the McMartin Preschool and Kelly Michaels Daycare abuse cases: A case study. Social Influence, 1, 16-47. doi: 
$10.1080 / 15534510500361739$

Scottish Executive. (2007). National curriculum joint investigative interviewing of child witnesses training in Scotland. Edinburgh, Scotland: Author.

Scottish Executive. (2011). Guidance on joint investigative interviewing of child witnesses in Scotland. Edinburgh, Scotland: Author.

Sommerville, J. A., \& Hammond, A. J. (2007). Treating another's actions as one's own: Children's memory of and learning from joint activity. Developmental Psychology, 43, 1003-1018. doi: 10.1037/0012-1649.43.4.1003

State of Michigan Governor's Task Force on Child Abuse and Neglect and Department of Health and Human Services. (2017). Forensic interviewing protocol ( $4^{\text {th }}$ ed.). https://www.michigan.gov/documents/dhs/DHS-PUB-0779_211637_7.pdf

Sternberg, K. J., Lamb, M. E., Hershkowitz, I., Yudilevitch, L., Orbach, Y., Esplin, P. W., \& Hovav, M. (1997). Effects of introductory style on children's abilities to describe experiences of sexual abuse. Child Abuse \& Neglect, 21, 1133-1146. doi: $10.1016 / \mathrm{S} 0145-2134(97) 00071-9$

Steward, M. S. \& Steward, D. S. (with Farquhar, L., Myers, J. E. B., Reinhart, M., Welker, J., Joye, N., Driskill J., \& Morgan, J.) (1996). Interviewing young children about body touch and handling. Monograph of the Society for Research in Child Development, 61 (4-5, Serial No. 248). doi 10.2307/1166205

Vrij, A. (2005). Criteria-based content analysis: A qualitative review of the first 37 studies. Psychology, Public Policy, and Law, 11, 3-41. doi: 10.1037/1076-8971.11.1.3

Walker, A. G. (with Kenniston, J., Inada, S. S., \& Caldwell, C.) (2013). Handbook on questioning children (3d ed.). Washington, DC: American Bar Association Center on 
Children and the Law.

Wang, Q., \& Peterson, C. (2014). Your earliest memory may be earlier than you think:

Prospective studies of children's dating of earliest childhood memories. Developmental Psychology, 50, 1680-1686. doi: 10.1037/a0036001

Wang, Q., \& Peterson, C. (2016). The fate of childhood memories: Children postdated their earliest memories as they grew older. Frontiers in Psychology, 6, 7. Retrieved from http://cmich.idm.oclc.org/login?url=http://search.proquest.com.cmich.idm.oclc.org/docvi ew/1845547599?accountid=10181

Wang, Q., Peterson, C., Khuu, A., Reid, C.P., Maxwell, K.L., \& Vincent, J.M. (2017). Looking at the past through a telescope: Adults postdated their earliest childhood memories. Memory. Advance online publication. doi: 10.1080/09658211.2017.1414268

Waterhouse, G. F., Ridley, A. M., Bull, R., La Rooy D., \& Wilcock, R. (2016). Dynamics of repeated interviews with children. Applied Cognitive Psychology, 30, 713-721. doi: $10.1002 /$ acp. 3246

Weinsheimer, C. C. (2016). Perceptions of credibility for a memory report of a single versus repeated event (master's thesis). Simon Fraser University, Burnaby, Canada. Retrieved from http://summit.sfu.ca/item/16588

Welle, A., Berclaz, M., Lacasa, M.-J., \& Niveau, G. (2016). A call to improve the validity of Criterion-Based Content Analysis (CBCA): Results from a field-based study including 60 children's statements of sexual abuse. Journal of Forensic and Legal Medicine, 43, 111119. doi: 10.1016/j.jflm.2016.08.001

Williams, S., Moore, K., Crossman, A. M., \& Talwar, V. (2016). The role of executive functions and theory of mind in children's prosocial lie-telling. Journal of Experimental Child 
Psychology, 141, 256-266. doi: 10.1016/j.jecp.2015.08.001

Winters, J. J., \& Semchuk, M. T. (1986). Retrieval from long-term store as a function of mental age and intelligence. American Journal of Mental Deficiency, 90, 440-448.

Wolfman, M., Brown, D., \& Jose, P. (2016). Taking stock: Evaluating the conduct of forensic interviews with children in New Zealand. Psychology, Crime \& Law, 22, 581-598. doi: 0.1080/1068316X.2016.1168426 
Table 1

How Children Talk about Events: Summary and Recommendations

\begin{tabular}{|c|c|c|}
\hline Principle & Implications for Interviewing & Implications for Analyzing Reports \\
\hline $\begin{array}{l}\text { 1. Children describe past events from } \\
\text { the time they can talk. }\end{array}$ & $\begin{array}{l}\text { Follow recommendations for accommodating } \\
\text { young children, such as scheduling } \\
\text { interviews at times when they are usually } \\
\text { alert and giving them adequate time to think } \\
\text { and respond. }\end{array}$ & $\begin{array}{l}\text { - Do not dismiss a report based solely on a } \\
\text { child's age at the time of an experience or } \\
\text { a report, but consider case features } \\
\text { associated with reliable testimony. }\end{array}$ \\
\hline $\begin{array}{l}\text { 3. Children report in piecemeal } \\
\text { fashion across open-ended } \\
\text { prompts. }\end{array}$ & $\begin{array}{l}\text { - Deliver a series of open-ended prompts. } \\
\text { - Return conversation back to the child by } \\
\text { using facilitators (e.g., "Uh huh"). } \\
\text { - Combine invitations ("Tell me what } \\
\text { happened") with cued invitations that ask } \\
\text { children to expand on something they already } \\
\text { mentioned ("Tell me about that time he took } \\
\text { pictures"). }\end{array}$ & $\begin{array}{l}\text { - Do not assume that event components } \\
\text { children reported late in a short series of } \\
\text { open-ended prompts, or after they said, } \\
\text { "That's all," are less reliable than } \\
\text { components mentioned earlier. } \\
\text { - Do not assume that statements such as, } \\
\text { "that's all I remember" inherently mean } \\
\text { that a child cannot elaborate. }\end{array}$ \\
\hline $\begin{array}{l}\text { 4. Children maintain accuracy across } \\
\text { a series of differently-worded } \\
\text { open-ended prompts. }\end{array}$ & $\begin{array}{l}\text { - Maintain open-ended prompting by varying } \\
\text { the wording of prompts. }\end{array}$ & $\begin{array}{l}\text { - Do not place more weight on responses to } \\
\text { the early open-ended prompt within a } \\
\text { series of open prompts. }\end{array}$ \\
\hline
\end{tabular}




\begin{tabular}{|c|c|c|}
\hline & $\begin{array}{l}\text { - Repeat the names of the people and actions } \\
\text { of interest rather than replacing these words } \\
\text { with words like "she" or "that." } \\
\text { - When children mention unexpected } \\
\text { happenings or details, ask questions to clarify } \\
\text { whether they are still talking about the matter } \\
\text { under investigation. }\end{array}$ & $\begin{array}{l}\text { - Ask adults in a child's life whether } \\
\text { unexpected narrative matches other } \\
\text { caregiving locations or innocuous events } \\
\text { the child might have remembered. } \\
\text { - Do not discredit a generally coherent } \\
\text { account simply because a fatigued child } \\
\text { began to talk off topic. }\end{array}$ \\
\hline $\begin{array}{l}\text { 8. Children's narratives contain detail } \\
\text { errors, and young children have } \\
\text { weaker filters for some types of } \\
\text { errors }\end{array}$ & $\begin{array}{l}\text { - Rely heavily on open-ended prompts because } \\
\text { this type of prompt elicits low rates of } \\
\text { fabrication errors. }\end{array}$ & $\begin{array}{l}\text { - Do not discredit the gist of a narrative } \\
\text { simply because minor details are } \\
\text { inconsistent with physical evidence or a } \\
\text { child's past testimony. } \\
\text { - Do not assume that everything a child } \\
\text { says is a relevant detail that must have } \\
\text { happened at some time or place. }\end{array}$ \\
\hline
\end{tabular}




\begin{tabular}{|c|c|c|}
\hline $\begin{array}{l}\text { 9. Focused questions often yield less } \\
\text { accurate responses than open- } \\
\text { ended prompts. }\end{array}$ & $\begin{array}{l}\text { - Avoid asking about unnecessary details. } \\
\text { - When possible, follow focused questions } \\
\text { with more open-ended prompts. }\end{array}$ & $\begin{array}{l}\text { To decide whether unexpected answers to } \\
\text { focused questions compromise the gist of } \\
\text { a report, consider the child's age, how the } \\
\text { question was worded, the length of time } \\
\text { since the event, and the level of detail } \\
\text { required by the question. } \\
\text { - Do not rely solely on the child's answers } \\
\text { to focused questions; instead, take into } \\
\text { account the entire case context and other } \\
\text { available evidence. }\end{array}$ \\
\hline $\begin{array}{l}\text { 10. Focused prompts do not always } \\
\text { effectively cue memories. }\end{array}$ & $\begin{array}{l}\text { Phrase prompts using simple, concrete } \\
\text { words. } \\
\text { - Avoid adding unnecessary words to prompts } \\
\text { that might restrict meaning. } \\
\text { - When children appear to contradict } \\
\text { themselves, ask follow-up questions to } \\
\text { double-check their intent. }\end{array}$ & $\begin{array}{l}\text { - Strike out contradictions that could have } \\
\text { been caused by well-known language or } \\
\text { memory phenomena before evaluating the } \\
\text { remaining information. }\end{array}$ \\
\hline $\begin{array}{l}\text { 11. Children's styles of reporting are } \\
\text { influenced by interviewers' styles } \\
\text { of asking. }\end{array}$ & $\begin{array}{l}\text { - Follow children's lead, prompting } \\
\text { generically when children disclose } \\
\text { generically and episodically when children } \\
\text { disclose episodically. } \\
\text { - Follow a series of generic prompts with } \\
\text { prompts about specific episodes. } \\
\text { - To plan effective episodic questions, listen } \\
\text { for episodic details spontaneously dropped } \\
\text { into accounts (e.g., "It's usually only the } \\
\text { weekends, but one time Uncle Jim picked me } \\
\text { up from school"). }\end{array}$ & $\begin{array}{l}\text { Episode-specific details of frequently- } \\
\text { occurring events and long-ago events are } \\
\text { not well retained. As a result, decisions } \\
\text { about whether a report is unexpectedly } \\
\text { sparse in details should take into account } \\
\text { how often and when the matters under } \\
\text { investigation allegedly occurred. } \\
\text { - Before concluding that an account is } \\
\text { lacking expected details, consider whether } \\
\text { the interviewer adequately probed for } \\
\text { specific episodes (if such information is } \\
\text { required in the case). }\end{array}$ \\
\hline
\end{tabular}




\begin{tabular}{|c|c|c|}
\hline in subsequent interviews. & $\begin{array}{l}\text { be permitted to follow their own trains of } \\
\text { thought, and interviewers should take time to } \\
\text { build rapport and privilege open-ended } \\
\text { prompts when children have been } \\
\text { interviewed previously. }\end{array}$ & $\begin{array}{l}\text { or fantastic) details with each additional } \\
\text { interview. }\end{array}$ \\
\hline $\begin{array}{l}\text { 13. Children who witnessed the same } \\
\text { event will recall it differently. }\end{array}$ & $\begin{array}{l}\text { Encourage complete accounts by delivering a } \\
\text { series of differently-worded open-ended } \\
\text { prompts, and encourage children to talk by } \\
\text { delivering facilitators (also called still-your- } \\
\text { turn feedback). } \\
\text { - Adding an interview break, followed by } \\
\text { another recall opportunity, might elicit new } \\
\text { details. }\end{array}$ & $\begin{array}{l}\text { - Ask whether accounts across witnesses } \\
\text { preserve the overall plot of an event or } \\
\text { whether children' collective accounts } \\
\text { contain numerous unexpected } \\
\text { contradictions. }\end{array}$ \\
\hline $\begin{array}{l}\text { 14. Event narratives can get better } \\
\text { and worse over time. }\end{array}$ & $\begin{array}{l}\text { Persist with open-ended prompts even if } \\
\text { children have been previously interviewed or } \\
\text { the event occurred a long time ago. }\end{array}$ & $\begin{array}{l}\text { Although new information could be the } \\
\text { product of suggestive influences, do not } \\
\text { automatically assume that children are } \\
\text { fabricating whenever later reports contain } \\
\text { age-appropriate descriptions that were } \\
\text { missing from earlier reports. }\end{array}$ \\
\hline $\begin{array}{l}\text { 15. False narratives can be detailed } \\
\text { and coherent. }\end{array}$ & $\begin{array}{l}\text { Elicit detailed narratives with nonleading } \\
\text { invitations. } \\
\text { - Support the overall investigation by planning } \\
\text { questions that will test alternative hypotheses } \\
\text { for allegations. }\end{array}$ & $\begin{array}{l}\text { Document whether, in light of the } \\
\text { principles described here, there is a } \\
\text { plausible and coherent story that is } \\
\text { unlikely to contain central details } \\
\text { provided by outside influences. } \\
\text { - Consider children's levels of cognitive } \\
\text { maturity and language proficiency, how } \\
\text { case features and interviewers' skills } \\
\text { would have impacted their memory } \\
\text { reports, and the social contexts of } \\
\text { children's lives. }\end{array}$ \\
\hline
\end{tabular}




\section{HOW CHILDREN TALK}

Table 2

Two Children's Accounts of Visiting a Friendly Pirate in La Rooy, Pipe, and Murray (2005, Experiment 1)

\section{Child A}

"I tipped some stuff in the bowl, and then I tipped some different stuff in it, and then I got the brush, and then I put it on the paper, and then I arr, did, and then we put it in the box, and then we looked around for a minute, and then she went bang, bang, bang, and ... then I tooked it out and it was the rubbish bin, and then I had to dig in it, and it was some treasure, then I opened it and there was some treasure. ... she got the key down for me, and I opened up the treasure."

\section{Child B}

"Well, umm, I put some paint on a piece of paper, and I put it in a box, and then I gave some something to eat to the bird, and, and, then I, then, then I, looked, and I found some treasure, I opened the treasure box, and there was gold and stuff in it. That's all."

Note: The interviewer's question was "So tell me everything that you can remember about v you visited the pirate." 


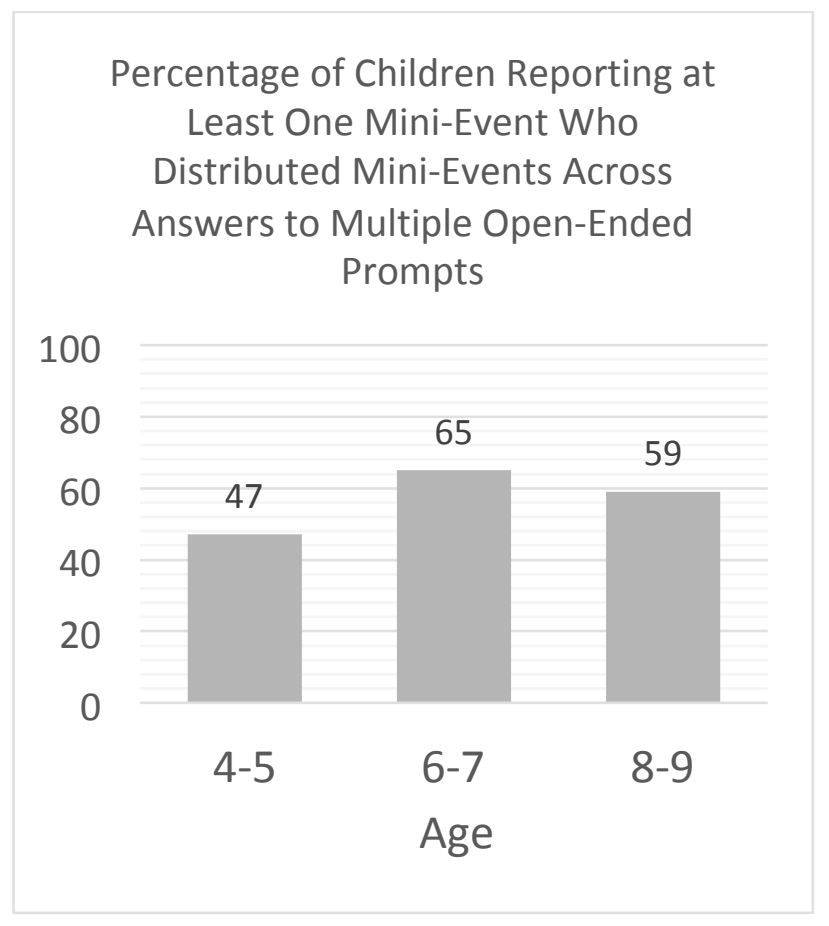

a.

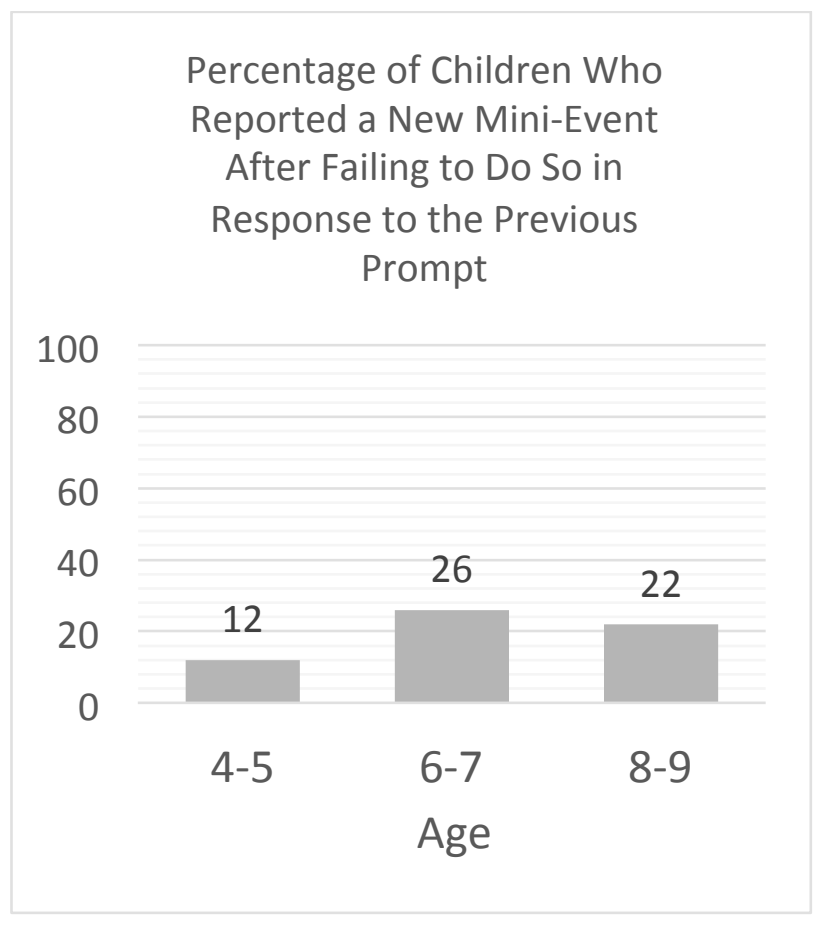

b.

Figure 1. Children recall events in piecemeal fashion: They distribute information about major event components (mini-events) across answers to multiple open-ended prompts (panel a) and sometimes report a new mini-event after failing to retrieve one earlier in the interview (panel b). 


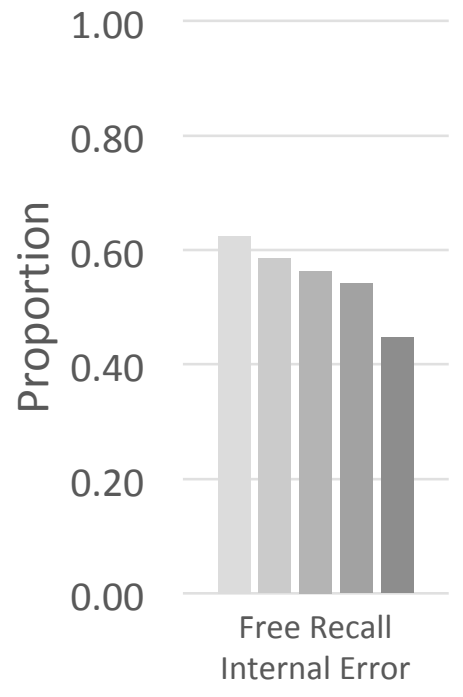

a.

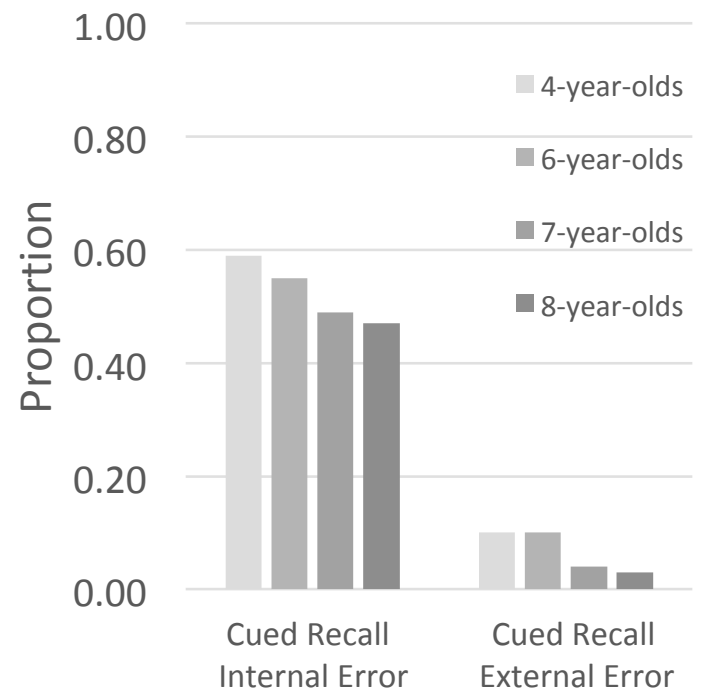

b.

Figure 2. Proportion of variable details reported in free recall that children attributed to the wrong event occurrence (panel a, $r_{\text {age, proportion internal errors }}=.16, p=.001$ ), and the proportion of meaningful responses to cued-recall questions about variable details that were internal and external intrusion errors (panel $\mathrm{b} ; r_{\mathrm{age}}$, cued recall internal error $=-.18, \mathrm{r}_{\text {age, } \text { cured recall external error }}=-.21, p \mathrm{~s} \leq$ $.001)$. 